\title{
Reprocessing of wood flour reinforced polypropylene composites: Impact of particle size and coupling agent on composite and particle properties
}

\author{
L. Soccalingame ${ }^{\mathrm{a}, 1}$, A. Bourmaud ${ }^{\mathrm{b}}$, D. Perrin ${ }^{\mathrm{a}, 1}$, J.-C. Bénézet ${ }^{\mathrm{a}, 1}$, A. Bergeret ${ }^{\mathrm{a}, *, 1}$ \\ a C2MA, Ecole des Mines d'Alès, 6 Avenue de Clavières, 30319 Alès Cedex, France \\ ${ }^{\mathrm{b}}$ LIMATB, Université de Bretagne Sud, Rue de Saint Maudé, 56321 Lorient Cedex, France
}

\begin{abstract}
A B S T R A C T
This work aims to understand the degradation induced by multiple injection molding cycles on numerous properties of wood flour reinforced polypropylene (PP) composites. The influence of the initial wood particle size was studied as well as the influence of the addition of polypropylene grafted with maleic anhydride (PPgma) as a coupling agent at a given rate. Biocomposite compounds (20wt\% of wood flour) are produced by twin-screw extrusion. Then, multiple injection and grinding cycles were performed (up to 7 cycles) to obtain normalized samples. The evolution of the wood flour particle characteristics is first assessed by SEM observation, size measurements and nanoindentation experiments. Then, the evolution of the PP matrix microstructure is determined by SEC tests (average molecular weight measurements), rheometer tests and DSC (polymer crystallinity). Finally, material mechanical properties are measured at a macro-scale thanks to tensile tests. Our experimental results show that the composite mechanical properties remain quite stable after 7 processing cycles despite wood flour degradation and PP degradation.
\end{abstract}

Keywords:

Recycling

Coupling agent

Nanoindentation

Spruce wood flour

Polypropylene

Composite

\section{Introduction}

The use of vegetal fiber reinforced composites is growing since several years. These composites mainly concern thermoplastic polymers reinforced by wood fibers or flour. This trend is mainly fueled by the building and the automotive industries. One of the most widespread materials is wood flour reinforced polypropylene (PP) composite that is mainly prevalent in the construction market. Assessing its recycling capability is up to now a challenging economic and scientific goal [1].

Stark and Berger [2] investigated the effects of particle size on the properties of PP filled with wood flour. They concluded that tensile modulus and strength decrease with increasing particle size beyond a $250 \mu \mathrm{m}$ average particle size. A previous work [3] also showed that fine flour filled composite presents a better strength and modulus and higher elongation than the coarse flour filled composite.

\footnotetext{
* Corresponding author.

E-mail address: anne.bergeret@mines-ales.fr (A. Bergeret).

1 C2MA is member of the European Polysaccharide Network of Excellence (EPNOE), www.epnoe.eu.
}

Another relevant parameter to consider is the fiber/matrix interface. Its quality is a prevalent topic of study because of its significance in the composite general properties. Given the poor adhesion between the natural fibers and the conventional polymer matrices, fiber surface treatments can be carried out. Among these, the addition of maleic anhydride grafted polypropylene (i.e. PPgma) is one of the most widespread. PPgma is able to bind PP macromolecular chains to hydroxyl groups present at the natural fiber surface thanks to ester bonds. In a wood sawdust flour reinforced polypropylene composite, tensile modulus and strength, flexural modulus and strength and impact strength were found to be improved by adding maleated PP (PPgma) [4]. Numerous works also show this tendency with various processing parameters, maleic anhydride contents and wood flour rates [5,6]. However, after a certain amount of this coupling agent, the tensile strength decreases because of its low molecular mass inducing a plasticization effect [7].

Thus, the effect of the wood particle size and the PPgma content on the properties is well known. However, these two factors are not studied during reprocessing cycles in order to simulate recycling in the case of wood flour reinforced PP.

Nevertheless, the reprocessing degradation of wood-fiber reinforced PP composites was studied by several authors among them 
Beg and Pickering [8]. They reported a gradual reduction of impact strength, tensile modulus and strength and an increase of the tensile elongation and crystallinity rate according to the successive processing cycles of composites. Bourmaud and Baley [9] compared thermal and mechanical properties of PP reinforced with hemp, sisal and glass fibers after reprocessing. SEM pictures display a length fiber reduction after reprocessing. After 7 processing cycles, they show that the tensile modulus decreases by $0.66 \%$ and by $10 \%$ for hemp and sisal fibers reinforced composites respectively and by $40 \%$ for the glass fiber reinforced composite. During processing, the natural fiber bundles are cut by their length but they also split into finer bundles and single fibers. The glass fibers only break by length and the diameter remains unchanged. Thus, the natural fiber aspect ratio (length/diameter $\mathrm{L} / \mathrm{D}$ ) is less affected than the glass fibers, and the mechanical performance is maintained while reprocessing natural fiber composites. The fiber length and the L/D ratio are two of the major key factors influencing the mechanical properties of a composite material [10]. Its decrease causes a lower rigidity and resistance. In case of a limited degradation of the matrix, the smaller fiber lengths may cause less fiber entanglement which leads to a more ductile composite material. The loss of impact resistance can be due to PP degradation by chain scission. Some rheological tests bring out a significant viscosity reduction, which can be mainly explained by PP chain scission [11-13].

In most processing studies, general properties of the composites are measured but not the evolution of the mechanical properties of the particles themselves. Wood flour is particles which are sensitive to the high temperatures in extrusion and injection processes. The measurement by nanoindentation of elastic modulus is proposed to assess the evolution of the wood flour particles properties (hardness and elastic modulus) through the successive processing cycles. The nanoindentation showed a considerable potential for in-situ and comparative analysis to obtain local mechanical information from the different constituting layers on plant cell walls. Nanoindentation tests are performed with a Berkovich-type indenter loading the wall at an angle of approximately $25^{\circ}$. Consequently, the resulting three-dimensional stress is not only a result of the deformations and thus modulus in longitudinal direction, but is also affected by the transverse and shear moduli (together microfibril angle and Poisson ratios) [14]. Thus owing to very different scales and solicitation modes, the average modulus of fibers measured by nanoindentation in longitudinal direction is low compared to the modulus obtained with conventional tensile tests $[15,16]$. In literature, nanoindentation was used for comparative studies in hair [17,18], wood [19,20] or bamboo cell walls [21]. Moreover, it is a suitable tool to estimate the decrease of cell wall mechanical properties induced by processing [15].

Thus, this paper aims to evaluate the influence of the wood particle size and of a PPgma coupling agent on the degradation of spruce wood flour reinforced PP composites after grinding and injection molding cycles (up to 7 cycles). The evolution of the wood flour particle characteristics is first assessed by SEM observation, size measurements and nanoindentation experiments. Then, the evolution of the PP matrix microstructure is determined by SEC tests (average molecular weight measurements), rheometer tests and DSC (polymer crystallinity). Finally, material mechanical properties are measured at a macro-scale thanks to tensile tests.

\section{Materials \& methods}

\subsection{Materials}

The matrix polymer was a standard homopolymer PP H733-07 grade supplied by Braskem Co. (Brazil) with a melt flow rate of $7.5 \mathrm{~g} / 10 \mathrm{~min}\left(230^{\circ} \mathrm{C}, 2.16 \mathrm{~kg}\right)$ according to the ISO1133 standard.
PPgma (Orevac ${ }^{\circledR}$ CA100) provided by Arkema Co. (France) was used as coupling agent with a $1 \% \mathrm{w} / \mathrm{w}$ grafting rate and was dry-mixed before processing at $5 \% \mathrm{w} / \mathrm{w}$ of the PP part. The wood flour is based on spruce wood and is obtained from AFT Plasturgie Co. (France). Some characterizations of the initial wood particles are presented in section 3.1. Two wood particle sizes were considered noted G1 and G2. Both wood flours were added at a content of $20 \%$ by weight in PP. Table 1 sums up the composition of the studied materials regarding the content by weight.

The processing methodology is summarized in Fig. 1 and the successive stages are detailed below.

\subsection{Compounding}

Prior to extrusion, the polymer granules have been dried at least $4 \mathrm{~h}$ at $80^{\circ} \mathrm{C}$ and the wood flour, $15 \mathrm{~h}$ at $80^{\circ} \mathrm{C}$. Table 2 reveals that these drying conditions induce a decrease of WF moisture content from around $4.8 \%-0.4 \%$ using a Karl Fisher method with a sample heated at $150{ }^{\circ} \mathrm{C}$.

In the subsequent phase, the PP matrix and the wood particles were mixed together in a BC21 Clextral co-rotating twin-screw extruder (step (1)). Its L/D ratio is 36 with a $25 \mathrm{~mm}$ screw diameter and a $900 \mathrm{~mm}$ screw length. The heating barrel is composed of 12 modules. Polymer pellets were fed in module 1 and the fiber incorporation was made through a feeding hopper located on module 5. Temperature was set at $180{ }^{\circ} \mathrm{C}$ along the barrel. The screw speed was arbitrarily fixed at $300 \mathrm{rpm}$, with a total feeding rate of $4 \mathrm{~kg} / \mathrm{h}$.

Extruded compound rods were cooled into water and rapidly dried by air pulsing before the granulating step. Pellets were kept overnight at $80{ }^{\circ} \mathrm{C}$ in a vacuum oven beforehand to remove the residual humidity (step (2)).

\subsection{Injection molding and grinding cycles}

The pellets were injection molded on a Krauss Maffei KM50T180CX. The temperature was fixed at $210{ }^{\circ} \mathrm{C}$ along the barrel. The mold was kept at $25^{\circ} \mathrm{C}$ by a water cooling system. The plastification and injection speeds were set respectively at $120 \mathrm{rpm}$ and $60 \mathrm{~cm}^{3} \mathrm{~s}^{-1}$. The samples were injected to obtain dog-bone samples ISO $1 \mathrm{~A}$ according to ISO 527-2 (step (3)). Some of them were grinded and injected multiple times (step (4)) while a set was characterized (step (5)).

The grinding process was performed in a RETSCH SM300 cutter mill to obtain flakes. The grinding process was carried out at $700 \mathrm{rpm}$ at room temperature with an $8 \mathrm{~mm}$ sieve. The flakes were stored at room temperature and vacuum dried overnight at $80{ }^{\circ} \mathrm{C}$ before injection molding. This protocol was accomplished $1,3,5$ and 7 times in order to purvey samples called P1, P3, P5 and P7 according to the number of passes they underwent (step (6)).

\subsection{Wood flour characterizations}

\subsubsection{TGA}

To determine the process temperature effect on wood particles, wood flour was tested by thermo-gravimetric analysis (TGA) using

Table 1

Composition of the studied materials.

\begin{tabular}{lll}
\hline & Wood flour content & PPgma content on the PP part \\
Neat PP & - & - \\
PP/WF G1 & $20 \% w / w$ & - \\
PP/WF G2 & $20 \% \mathrm{w} / \mathrm{w}$ & - \\
PP/PPgma/WF G2 & $20 \% \mathrm{w} / \mathrm{w}$ & $5 \% \mathrm{w} / \mathrm{w}$ \\
\hline
\end{tabular}




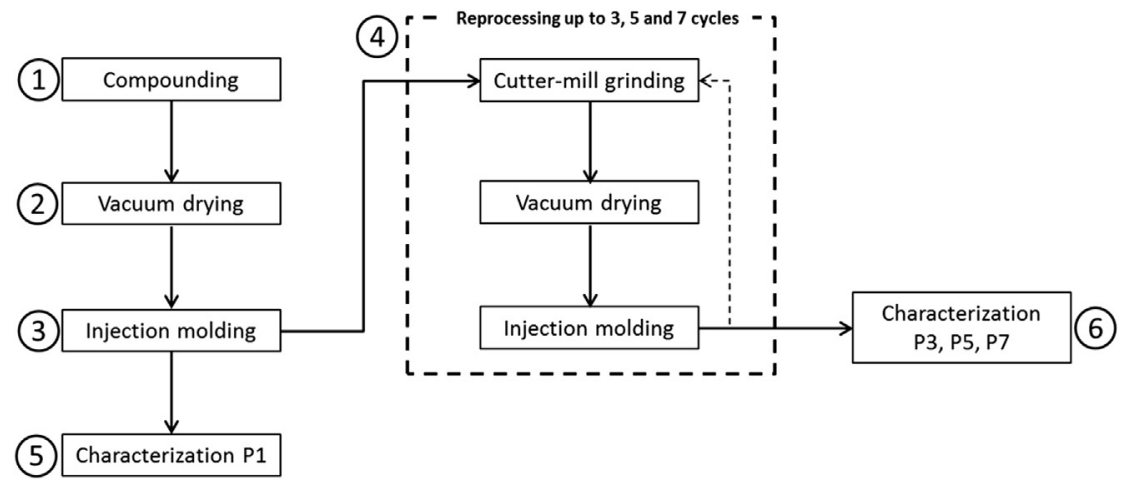

Fig. 1. Stages of the processing method by grinding and injection.

Table 2

Characterizations of the initial wood particles.

\begin{tabular}{|c|c|c|c|c|c|c|c|c|}
\hline \multirow[b]{3}{*}{ WF G1 } & \multirow{2}{*}{\multicolumn{2}{|c|}{$\begin{array}{l}\text { Indentation } \\
\text { modulus (GPa) }\end{array}$}} & \multirow{2}{*}{\multicolumn{2}{|c|}{$\begin{array}{l}\text { Indentation } \\
\text { hardness (GPa) }\end{array}$}} & \multicolumn{4}{|c|}{ Moisture content (\%) } \\
\hline & & & & & \multicolumn{2}{|c|}{ Before drying } & \multicolumn{2}{|c|}{ After drying } \\
\hline & 10.8 & \pm 2.3 & 0.26 & \pm 0.08 & 4.9 & \pm 1 & 0.4 & \pm 0.2 \\
\hline WF G2 & 9.2 & \pm 1.5 & 0.3 & \pm 0.06 & 4.7 & \pm 0.4 & 0.4 & \pm 0.3 \\
\hline
\end{tabular}

a Perkin Elmer Pyris-1 instrument. Measurements were performed under air flow from $25^{\circ} \mathrm{C}$ to $900^{\circ} \mathrm{C}$ with a heating rate of $10^{\circ} \mathrm{C} / \mathrm{min}$.

\subsubsection{Scanning electron microscopy (SEM)}

Wood flour dispersion and cell wall were analyzed through scanning electron microscopy (SEM). An Environmental Scanning Electron Microscope (ESEM) Quanta FEG 200 was used.

For the wood flour analysis within the composites, cross-section samples of composites were prepared through the same methodology. They were obtained from the middle part of the dog-bone samples. Then, they were embedded in epoxy resin and the surfaces were carefully polished.

The magnifications were $\times 80$ to determine the dispersion, $\times 2$ 000 to assess the general morphology of the wood cells and $\times 10$ 000 in order to observe the wood/matrix interface.

\subsubsection{Wood particles size measurements}

Wood particles size was determined all along the processing steps. Approximately $0.5 \mathrm{~g}$ of $\mathrm{PP} / \mathrm{WF}$ composite fragments was introduced into $20 \mathrm{~mL}$ of decalin (decahydronaphthalene). This solution was heat at $150{ }^{\circ} \mathrm{C}$ and agitated during $30 \mathrm{~min}$, sufficient to dissolve the whole PP matrix. The wood particles were sampled from the solution with a glass pipette. Then, 2 drops were laid on a glass side and observed by optical microscope (Leica WILD M10). Crossed polarizers were used to enhance the contrast and help the outline detection of the wood flour. Previous efforts from Le Moigne et al. have demonstrated the effectiveness of this method to detect cellulosic fibers which are highly crystalline and thus birefringent under polarized light [23]. In the case of wood flour, some bundles do not appear on the thresholded pictures because of their brown color.

As shown in Fig. 2, a brown particle is visible on the polarized picture. After thresholding the image, this particle does not appear because of its too dark color that is not distinguishable for Aphelion software from the black background. These brown particles are mainly the biggest particles and are lignin-rich bundles which are not crystalline contrary to cellulosic ones. As a consequence, some of the biggest particles were not measured as they are not distinguished after image processing. So, average size results were reduced because of this phenomenon.
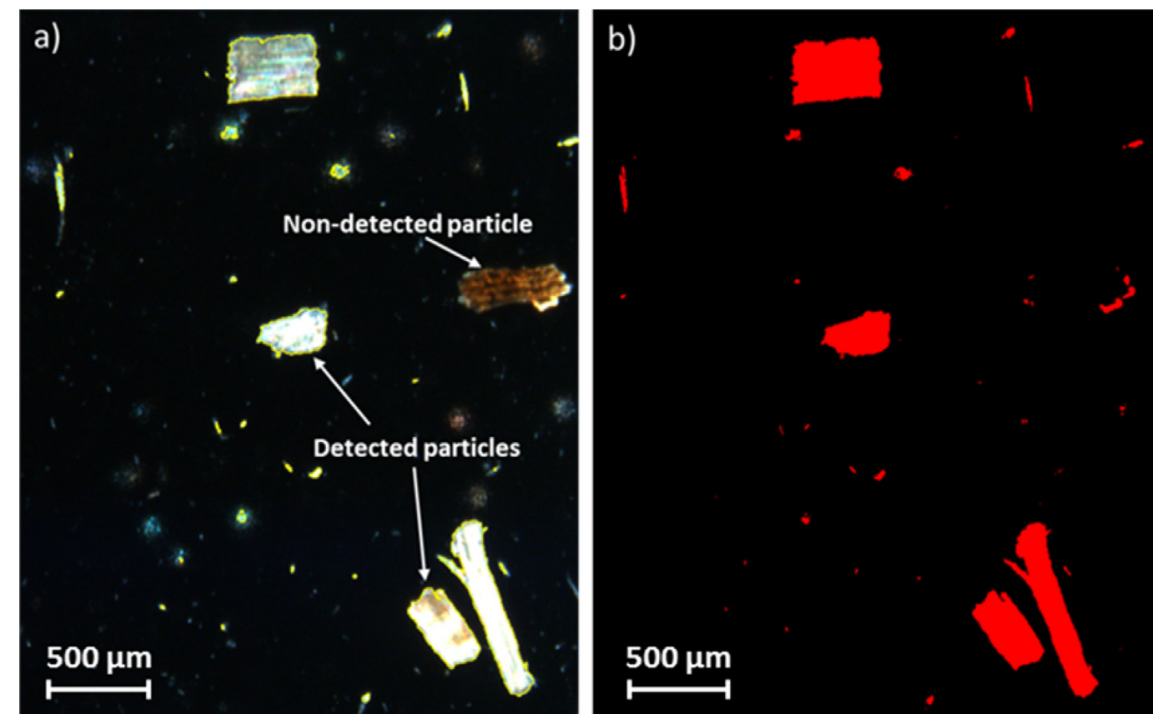

Fig. 2. Microscopic picture of wood flour particles under polarized light before (a) and after (b) image thresholding by Aphelion@ software. 


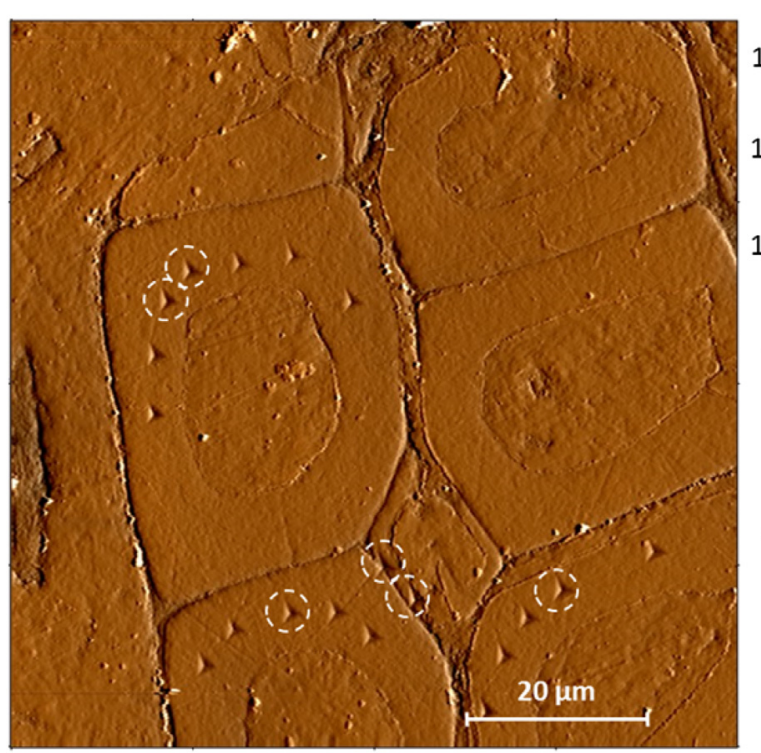

$\mathrm{nm}$

1400

1200

1000

800

600

400

200

Fig. 3. AFM cartography of indented surface of the PP/WF G2 composite.

Pictures were taken at $\times 10$ magnification with a Leica DFC 420 camera. 3 glass slides of 10 images were used for each material at the different reprocessing stages. The image processing and analyses were carried out using Aphelion $\odot$ software developed by ADCIS, France. The overlapping particles were removed by manual correction. The quantity of analyzed particles was about 10000 per material and per processing stage.

Fig. 6 shows microscopic pictures of WF G1 and WF G2 and no specific shape is identified as one can see fibers, bundles and other very fine particles with random shapes. So, an equivalent diameter parameter was measured with Aphelion@ $\odot$ software. It corresponds to the diameter of the circle whose area is equal to the area of the measured object. As a wide result scattering was observed for wood particle size nanoindentation measurements, a box plot representation was used according to the Fig. 4.

\subsubsection{Nanoindentation}

Nanoindentation tests were performed in order to determine the indentation modulus and hardness of wood flour either before processing or when it is incorporated in PP during the processing cycles.

Similar cross-section samples as those used for SEM analysis used to perform nanoindentation tests. Indentation tests were performed with a commercial nanoindentation system (Nanoindenter XP, MTS Nano Instruments) at room temperature $\left(23^{\circ} \mathrm{C} \pm 1\right)$. A continuous stiffness measurement (CSM) technique was carried out. In this technique, an oscillating force at controlled frequency and amplitude is superimposed onto a nominal applied force. The material, which is in contact with the oscillating force, responds with a displacement phase and amplitude [22]. Strain rate during loading was maintained at $0.05 \mathrm{~s}^{-1}$. The amplitude was $3 \mathrm{~nm}$ with a $45 \mathrm{~Hz}$ oscillation. The used tip is a Berkovich diamond tip. The depth penetration was set at $400 \mathrm{~nm}$.

For each material analyzed, about 60 indentations were made on the wood flour particles. 30 to 55 indents were retained. Each indent position was checked by AFM imaging thanks to an in-situ DME (Hannover, Germany) Dualscope 95-200 AFM equipment. Fig. 3 shows the indent at the wood cell wall surface by AFM topography. Some of them were carried out at the interface of two walls and possibly in the middle lamella as no specific wall was targeted during these tests.

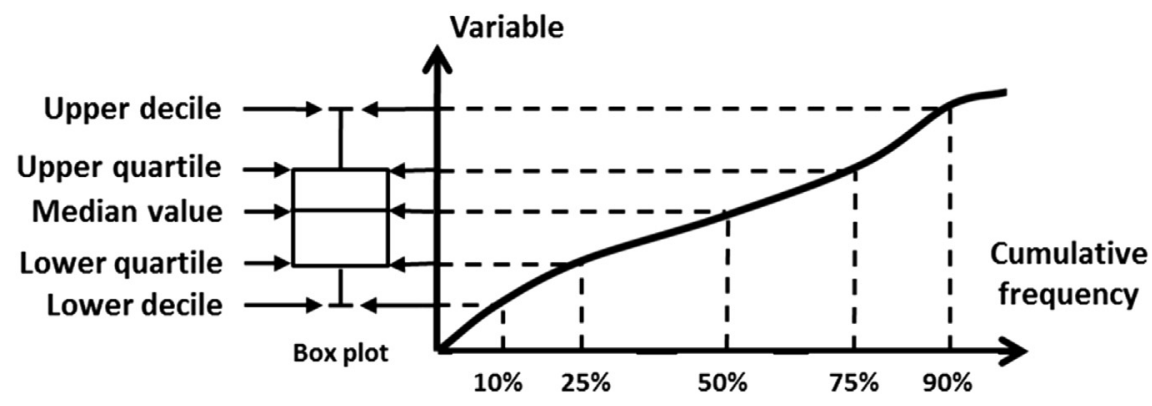

Fig. 4. A schematic presentation of the box plot method based on the cumulative distribution function of an experimental data set.

a)

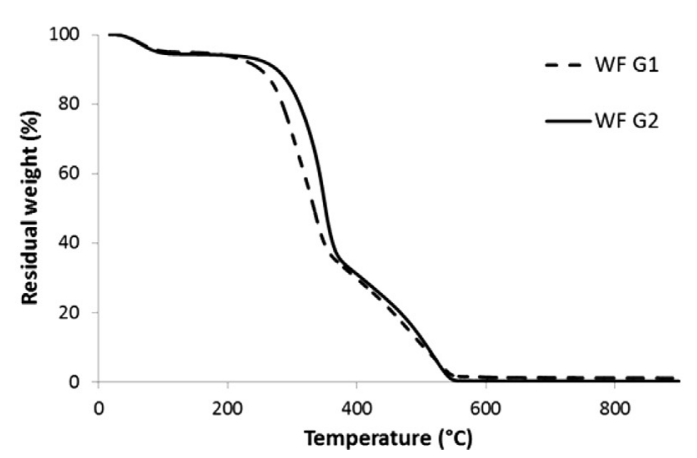

b)

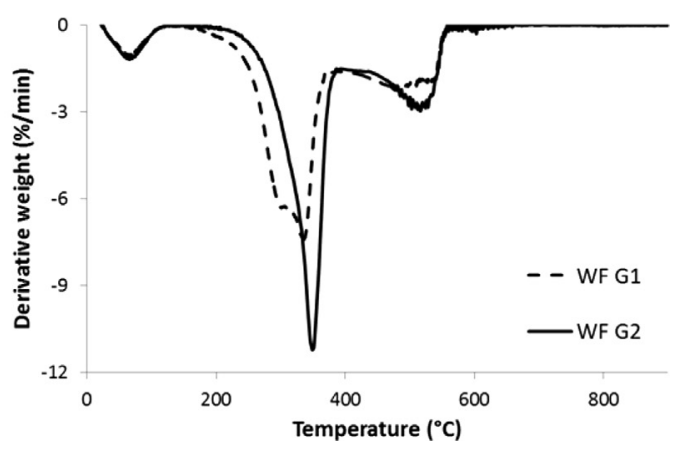

Fig. 5. Residual weight (a) and derivative weight (b) of WF G1 and WF G2 by TGA under an air atmosphere. 

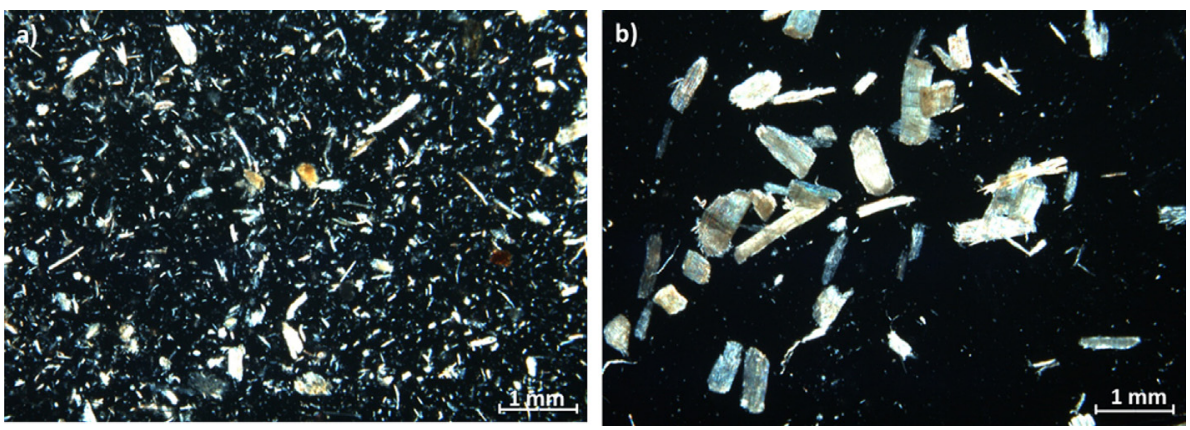

Fig. 6. Microscopic observations with a crossed polarized light of the two types of wood flour: WF G1 (a) and WF G2 (b) (magnification $\times 10$ ).

As a wide result scattering was observed for nanoindentation measurements, a box plot representation was used in order to facilitate analyses and identify tendencies [23]. As shown in Fig. 4, the bottom and top of the box represent the value of the studied variable corresponding to the lower and upper quartiles (the 25th and 75 th percentiles, respectively) of the cumulative distribution. The line inside the box corresponds to the median value (the 50th percentile) and the ends of the whiskers correspond to the lower and upper deciles (the 10th and 90th percentiles, respectively).

\subsection{Polypropylene matrix characterizations}

\subsubsection{Size-exclusion chromatography (SEC)}

The evolution of average molecular weights (in number $\overline{\mathrm{Mn}}$ and in weight $\overline{\mathrm{Mw}}$ ) of PP in neat PP and PP/WF composites was studied to evaluate the effect of successive processing cycles on the PP degradation. Size-exclusion chromatography was performed by Catalyse Co. (Marseille, France). Fragments were cut into the injected samples and solubilized into 1,2,4-trichlorobenzene (TCB) at a concentration of $3 \mathrm{mg} / \mathrm{mL}$. These solutions were agitated at $150{ }^{\circ} \mathrm{C}$ and, then filtered before test. The separation was carried out by using a pre-column PLgel Olexis Guard $7.5 \times 50 \mathrm{~mm}$ and three PLgel Olexis Guard $7.5 \times 300 \mathrm{~mm}$ columns. The temperature was set at $150^{\circ} \mathrm{C}$, and the flow rate was $1 \mathrm{~mL} / \mathrm{min}$. The solvent was $1,2,4-$ trichlorobenzene (TCB) with $0.2 \mathrm{mg} / \mathrm{L}$ of butylhydroxytoluol (BHT) added to stabilize the polymer against oxidative degradation. The standard deviation was determined from two measurements per sample and is included in the 3\%-5\% range for $\overline{\mathrm{Mn}}$ and $5 \%-8 \%$ for Mw.

\subsubsection{Rheological measurements}

The evolution of the rheological material properties directly reflects changes in molecular parameters such as the chain scission or crosslinking phenomena. Thus, dynamic rheological measurements were carried out to assess the change in complex viscosity using an ARES rheometer (Rheometric Scientific). The melt viscoelasticity tests in oscillatory shear mode were performed with parallel plate equipment at a fixed temperature of $180^{\circ} \mathrm{C}$. The plate diameter was $25 \mathrm{~mm}$ and the gap between them was $1 \mathrm{~mm}$. A frequency sweep was carried out from 0.1 to $100 \mathrm{rad} / \mathrm{s}$ for each experiment.

The samples were cut into the injected dog-bone shaped samples and placed between the parallel plates. Once the fixed temperature is reached, the gap is controlled at $1 \mathrm{~mm}$. Then, the molten excessive matter is removed and the test is started. At least 3 tests were performed for each material.

\subsubsection{Differential scanning calorimetry (DSC)}

The melting and crystallization behaviors of PP and PP/WF were assessed for every processing steps through differential scanning calorimetry (DSC) using a Perkin Elmer apparatus (Pyris Diamond) equipped with a cooling attachment, under a nitrogen atmosphere. Two heating steps interspersed with a cooling step from $20^{\circ} \mathrm{C}$ to $210{ }^{\circ} \mathrm{C}$ at a constant rate of $10^{\circ} \mathrm{C} /$ min were carried out. The sample weights were approximately $10 \mathrm{mg}$. They were analyzed in standard aluminium DSC pans. At least, 2 specimens were used for each test to ensure reproducibility. Melting temperature and enthalpy were obtained from the 2 nd heating step. The crystallinity ratio $\chi_{c}$ was calculated according to this Equation (1):

$\chi_{c}=\frac{\Delta H m}{\Delta H m_{100 \%} \times M_{P P}} \times 100$

where $\Delta \mathrm{Hm}$ is the melting enthalpy of the matrix polymer in the composite and $\Delta \mathrm{Hm}_{100 \%}$ is the melting enthalpy for a $100 \%$ crystalline PP polymer. It is considered equal to $209 \mathrm{~J} / \mathrm{g}$ [24]. $\mathrm{M}_{\mathrm{PP}}$ is the PP matrix content by weight in the composite. As the wood flour content is $20 \% \mathrm{w}$ for each composite, $\mathrm{M}_{\mathrm{PP}}$ is considered equal to 0.8 .

\subsection{Composite mechanical characterization}

\subsubsection{Tensile tests}

Classical tensile tests were performed to determine mechanical properties of PP and PP/WF composites. The apparatus used for these tensile tests is a Zwick Z010 with a $10 \mathrm{kN}$ load cell and a ClipOn extensometer for displacement measurements during modulus tests. These tests were performed according to the ISO 527 standard: the crosshead speed is set at $1 \mathrm{~mm} / \mathrm{min}$ for the tensile modulus measurements, $50 \mathrm{~mm} / \mathrm{min}$ for the break property measurements. Thus, Young modulus, strength and deformation were determined as a function of the reprocessing steps (P1, P3, P5 and P7). 5 measurements were carried out for modulus measurements and for strength and elongation at break measurements.

\section{Results and discussion}

\subsection{Characterization of particle size and mechanical characteristics of initial wood particles}

TGA measurements on WF G1 and WF G2 show typical wood thermal decomposition curves (Fig. 5). One can see three main peaks for both samples. The first peak below $100^{\circ} \mathrm{C}$ is attributed to moisture evaporation. The second peak between 200 and $400{ }^{\circ} \mathrm{C}$ includes extractive decomposition, hemicellulose decomposition and cellulose decomposition. The third peak between 450 and $600{ }^{\circ} \mathrm{C}$ is attributed to lignin decomposition [25]. As injection molding cycles were performed at $210^{\circ} \mathrm{C}$, it can be supposed that extractive and hemicellulose decompositions occur during these successive processing cycles. Otherwise, WF G1 starts to 
decompose before WF G2. Thus, WF G1 seems more sensitive to thermal degradation.

Wood flour size before processing was measured through image analysis (Fig. 6). One can see that WF G1 is mainly composed of fine particles with heterogeneous size. In contrary, WF G2 is composed of coarse particles with a small amount of fine ones. Fig. 7 presents the size distribution curves in number of WF G1 and WF G2 measured through image analysis and confirms these visual observations. The box plot indicates that the mean equivalent diameter is $68 \mu \mathrm{m}$ for the finest WF, i.e. WF G1, and $108 \mu \mathrm{m}$ for the coarsest, i.e. WF G2. As explained in section 2.5.2, the measured is under-estimated because of the non-detected lignified particles. This under-estimation is more significant for WF G2 as it contains more lignin-rich bundles. Thus some particles above $200 \mu \mathrm{m}$ were not detected. Otherwise, the box plot representation shows a wider size distribution for WF G2.

Indentation modulus and hardness were measured on the wood particles before extrusion by nanoindentation (Table 2). Average indentation modulus and hardness of about $10 \mathrm{GPa}$ and $0.3 \mathrm{GPa}$ respectively were obtained.

These values could be compared with literature data despite an important diversity of variety or cell walls. Many authors studied the indentation properties of wood cell walls. Gacitua et al. [26] found indentation modulus between 8 and $11 \mathrm{GPa}$ on eucalyptus cell walls and Bytebier et al. [27] 12-14 GPa by working on chestnut mature tension wood; these values are similar to ours. Nevertheless, in some cases, indentation modulus could be higher as exhibited by Wimmer et al. [27-29] on spruce wood (between 13 and $21 \mathrm{GPa}$ ). This important difference with our data could be explained by the orientation of the wood particles; indeed, the microfibrillar angle (MFA) of the wood cells has a preponderant influence on the measured indentation stiffness [14,19]. Thus, depending of the particle orientation which isn't controlled within the injected composite, indentation modulus values could be very scattered.

In opposition, the indentation hardness is more reproducible and generally included between 0.25 and $0.4 \mathrm{MPa}$ for wood cell walls $[19,28-30]$ which is consistent with our values. Contrary to the modulus, the indentation stiffness is not influenced by the MFA but mainly by the cell wall hemicellulosic matrix [31]. Consequently indentation values are similar if the cell wall biochemical compositions are close.

The moisture content is measured by a Karl-Fisher method and indicates the effect of the drying conditions before extrusion. A reduction in moisture content from about $5 \%$ to $0.5 \%$ was obtained for both WF.

\subsection{Effect of the wood flour size on the composites properties during the processing cycles}

\subsubsection{Evolution of wood flour particles}

Fig. 8 and Fig. 9 present SEM cross sections of PP/WF G1 and PP/ WF G2 along the processing cycles. The wood particle morphology and size reveal to be modified after 7 cycles. A breakdown of the coarser wood particles can be observed due to high shear rates during processing and grinding steps. This tendency is the most

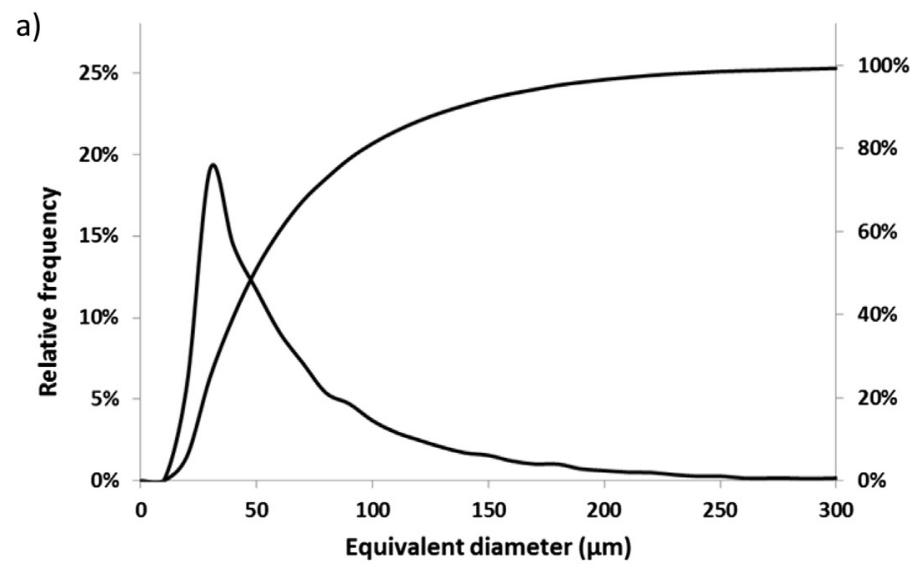

b)

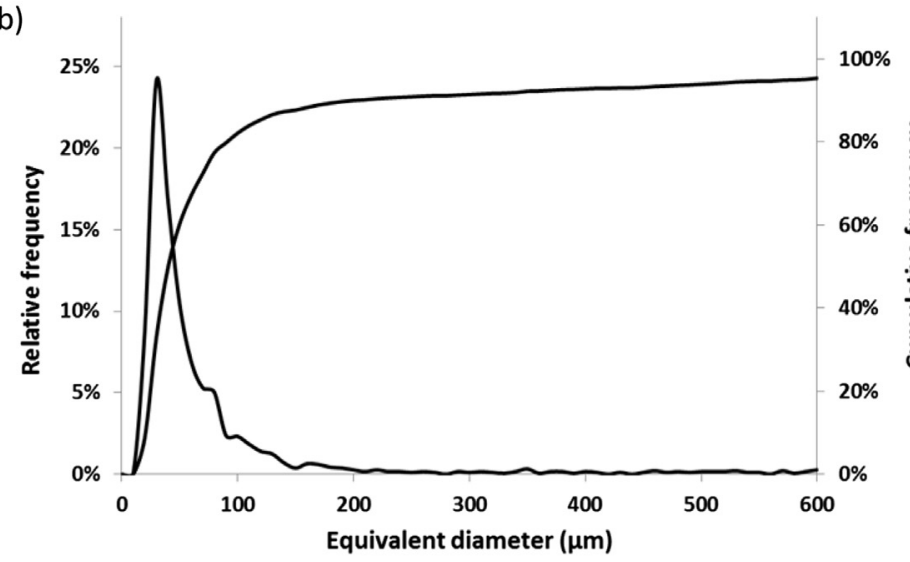

c) 250

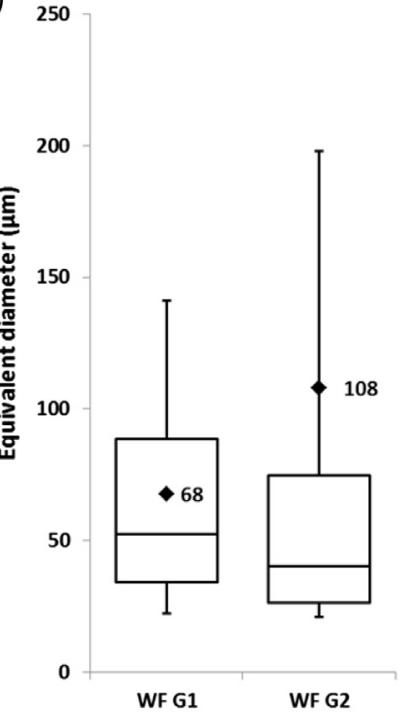

Fig. 7. Relative and cumulative size distribution in number of WF G1 (a) and WF G2 (b), box plot representation of WF G1 and WF G2 and mean size (square dots) (c). 

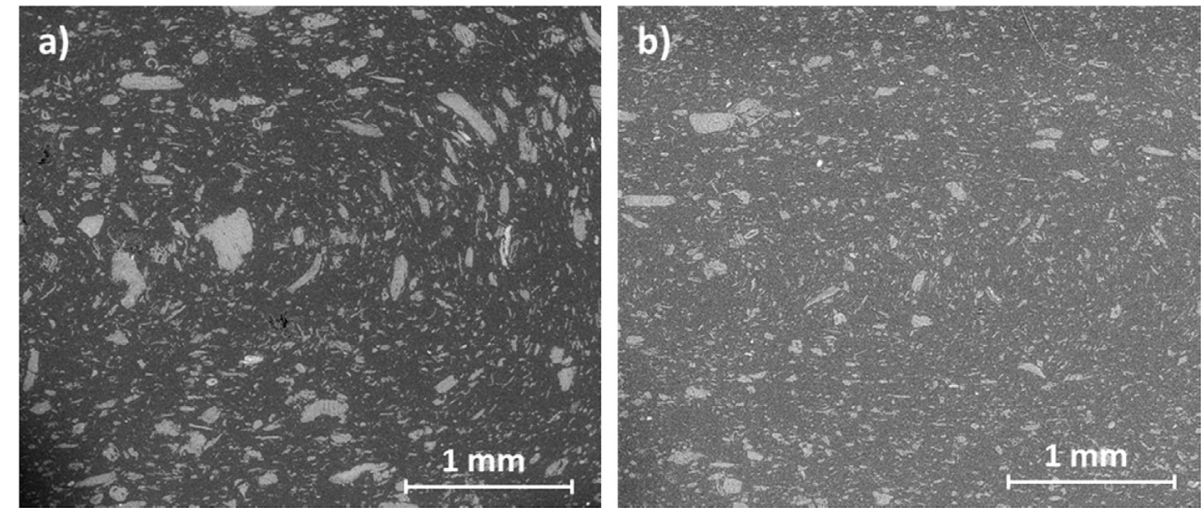

Fig. 8. SEM micrographs of transversal cross sections of PP/WF G1 at P1 (a) and at P7 (b) (magnification $\times 80$ ).

visible in the case of WF G2 where the numerous bundles are breaking progressively. WF G1 seems to be less sensitive thanks to its smaller initial size. As these coarse particles progressively disappear, the dispersion become more and more homogeneous along the cycles.

Fig. 10 shows the equivalent diameter of WF G1 and WF G2 measured after PP dissolution. These statistical results indicate a slight decrease of particle size caused by processing. However, one can see a progressive decrease of the population of the coarser particles (upper decile) according to the previous visual observations on SEM micrographs. Moreover, in the case of WF G2 (Fig. 10b), the greatest drop of this population occurred after the extrusion and the first injection cycle and the average equivalent diameter varies from $108 \mu \mathrm{m}$ to $70 \mu \mathrm{m}$. Thus, coarse particles are more sensitive to breakdown than small particles. Afterwards, the impact of the reprocessing cycles is very weak on the size evolution of particles under $70 \mu \mathrm{m}$. It means that the process has no effect under this critical equivalent diameter. This critical size phenomenon has been already observed in the case of the reprocessing of flax fibers reinforced PP [32].

Fig. 11 indicates the equivalent diameter distribution for WF G1 and WF G2. Particles with an equivalent diameter under $20 \mu \mathrm{m}$ were excluded. WF G1 shows that the number of coarse particles (above $80 \mu \mathrm{m}$ ) decreases with the cycles. Moreover, the population of finest particles (fewer than $60-80 \mu \mathrm{m}$ ) also increases as they break. In contrary, WF G2 shows that the population above $50 \mu \mathrm{m}$ increases. This tendency can be explained by the nondetected and lignin-rich biggest particles (cf. section 2.5.2) at the first cycles (above $200 \mu \mathrm{m}$ ) which break progressively into finer particles.
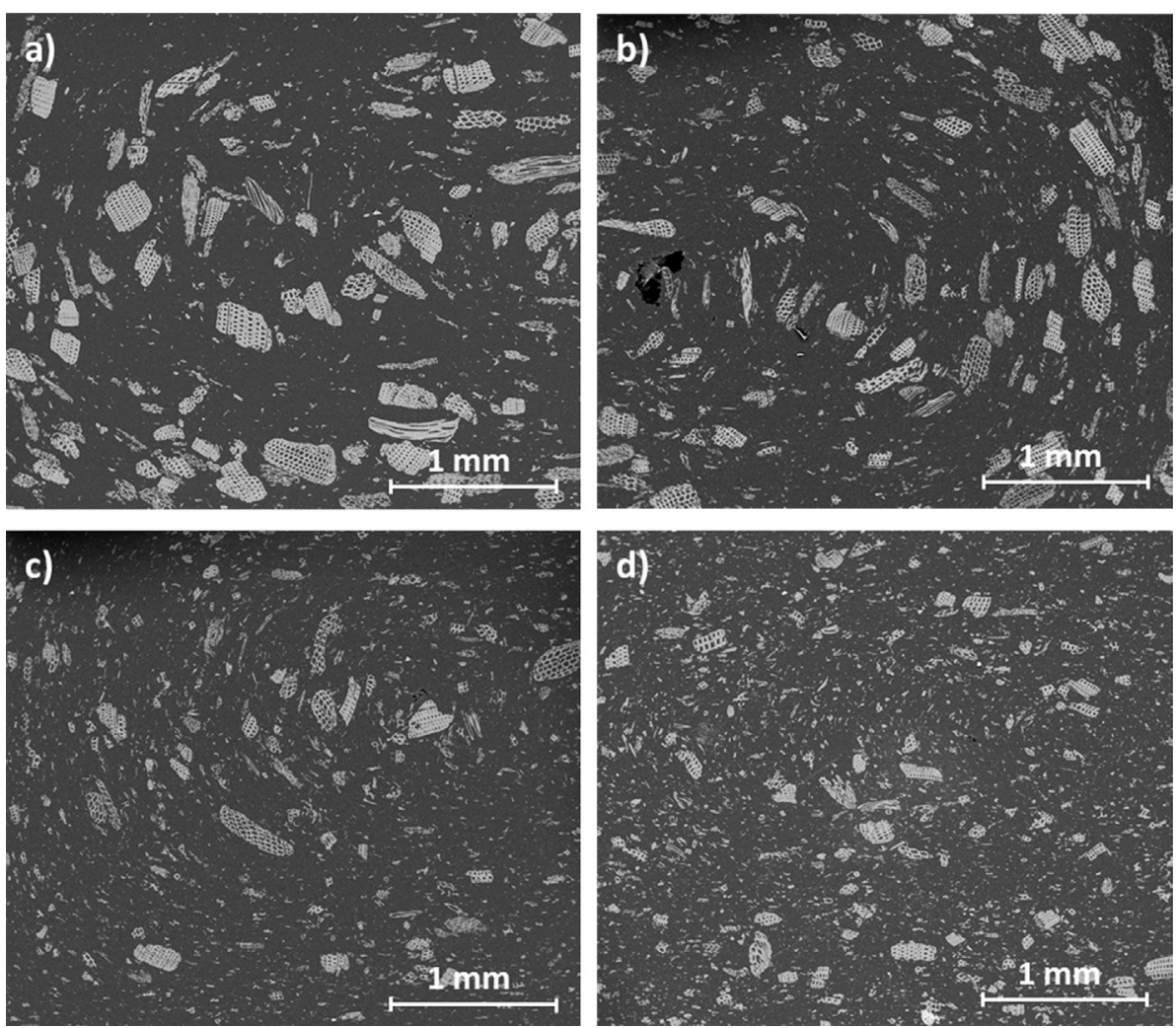

Fig. 9. SEM micrographs of transversal cross sections of PP/WF G2 at P1 (a), P3 (b), P5 (c) and P7 (d) (magnification $\times 80$ ). 

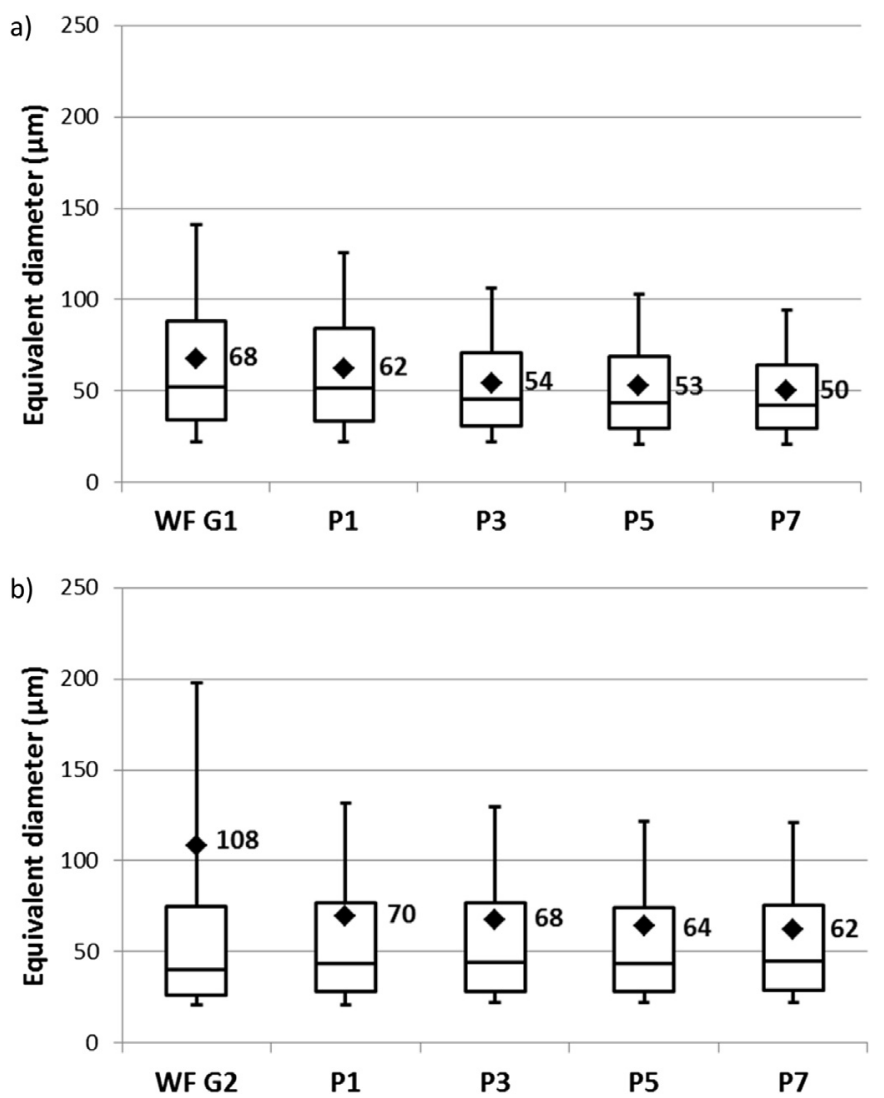

Fig. 10. Box-plot representation and average (square dots) of the equivalent diameter of WF G1 (a) and WF G2 (b) as a function of processing cycles.

Fig. 12 shows the intrinsic modulus and hardness results of the wood particle measured by nanoindentation after the cycles for both composites.

On one part, the moduli of WF G1 and WF G2 (Fig. 12a and c) presents maximum values at P3 and P5 in both case. Otherwise, these results do not show a clear tendency through the cycles and present a great variability of the measurements. Because the particle orientation is not controlled, this can be mainly explained by a misalignment between the longitudinal cell axis and the direction of indentation which leads to measurements strongly dependent on microfibril angle into the wood cell walls [33] [19]. Moreover since any specific wall was targeted in the particles, discrepancies can also be due to structural differences between the middle lamella, primary wall and secondary walls.

On the other part, despite a wide scattering, the hardness results (Fig. 12b and d) indicate a significant wood cell wall hardening until P5. As assumed by Konnerth [33] and Gindl [19], the hardness behavior is dominated by polymers constituting the wood cell matrix, i.e. hemicellulose and lignin. The observed tendency may be explained by a degradation of polymers contained in wood cell walls during the successive processing cycles. Furthermore, Yildiz et al. [34] observed that the intrinsic mechanical properties of spruce wood samples decrease by heightening the temperature and duration of a heat treatment. It is mainly correlated to a degradation of hemicellulose components. Indeed, as seen in Fig. 5, TGA curves show that hemicellulose begins to degrade at $200{ }^{\circ} \mathrm{C}$, and injection cycles were performed at $210{ }^{\circ} \mathrm{C}$. Hosseinaei et al. [35] showed a strong drop of the wood elastic modulus after a hemicellulose extraction with the nanoindentation technic. They also related a change in lignin arrangement, i.e. the lignin can melt, coalesce and migrate from the cellulose microfibril surfaces
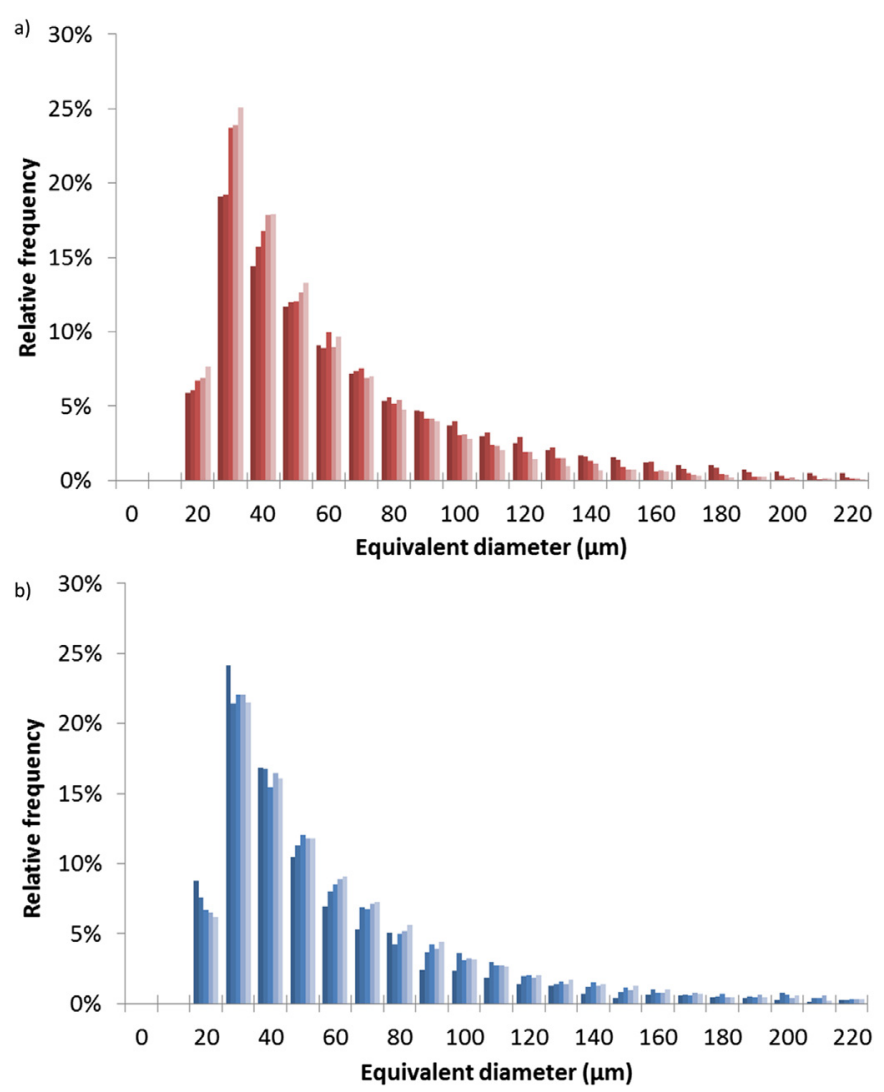

Fig. 11. Comparison of relative frequency by number of the particle equivalent diameter of WF G1 (a) and WF G2 (b) as a function of processing cycles from the initial state (darker color) to P7 (lighter color).(For interpretation of the references to colour in this figure legend, the reader is referred to the web version of this article.)

because of the high process temperature. In both composite, P7 presents a very great dispersion and a lower mean value than P5. It may be attributed to a migration of lignin components at the cell wall surfaces related by Hosseinaei [35].

Besides, color change from P1 to P7 as presented in Fig. 13 shows a darkening of the initial brown colour (in web version) for $\mathrm{PP} / \mathrm{WF}$ $\mathrm{G} 2$. It can be attributed to the degradation of hemicellulose but also to the migration of lignin components from the wood particles as mentioned for the nanoindentation results. The same trend was observed for PP/WF G1.

\subsubsection{Evolution of PP matrix}

Table 3 presents the change in chain length (molecular weights $\overline{\mathrm{Mn}}$ and $\overline{\mathrm{Mw}}$ ) of PP as a function of the processing cycles. An increase in both $\overline{\mathrm{Mn}}$ and $\overline{\mathrm{Mw}}$ values is observed in presence of wood flour. Moreover, one can see that this increase does not occur at the extrusion stage which was performed at $180^{\circ} \mathrm{C}$ but only after the first injection cycle $(\mathrm{P} 1)$ performed at $210^{\circ} \mathrm{C}$. We suppose that some natural polymer components, especially hemicellulose components degrade and/or migrate from the wood cell wall and bind with the analyzed PP macromolecules during SEC tests.

As concerns neat PP, an erratic variation of $\overline{\mathrm{Mn}}$ was obtained (especially for P5 and P7) with no significant evolution in $\overline{\mathrm{Mw}}$. This result may suggest that competitive degradation mechanism occurs up to 5 processing cycles, such as chain scission and crosslinking. As crosslinking should increase the viscosity, the strong drop observed for the Newtonian viscosity leads to suppose that there is mainly a chain scission caused by a thermal oxidation of PP. Moreover, as neat PP is generally supplied with antioxidants 
a)

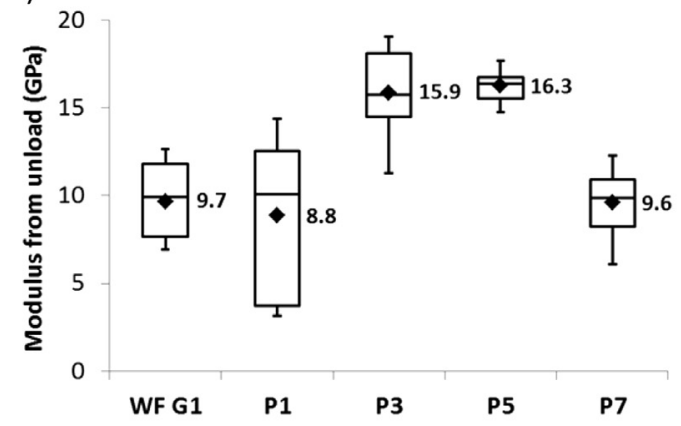

c)

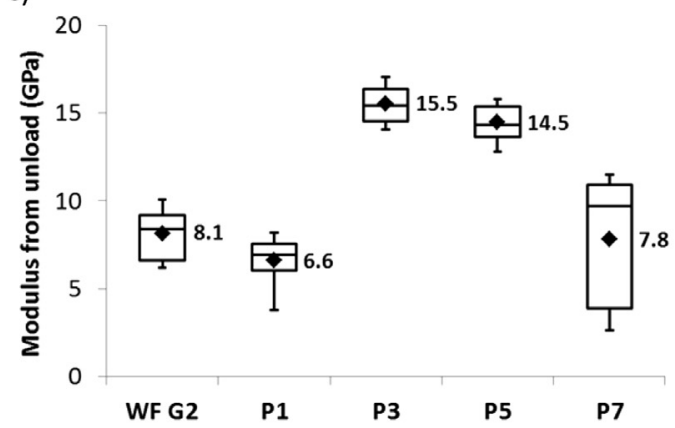

b)

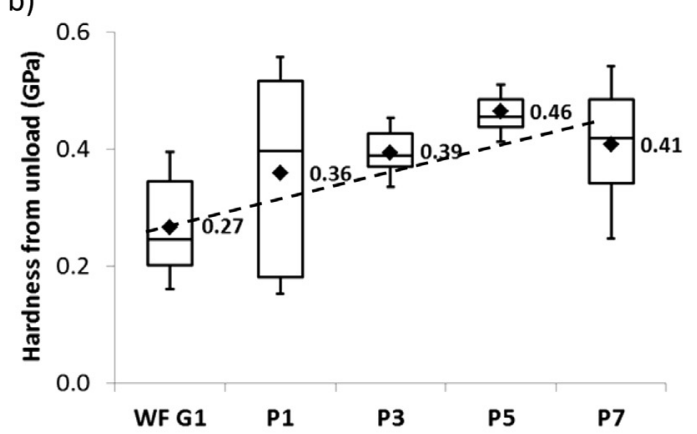

d)

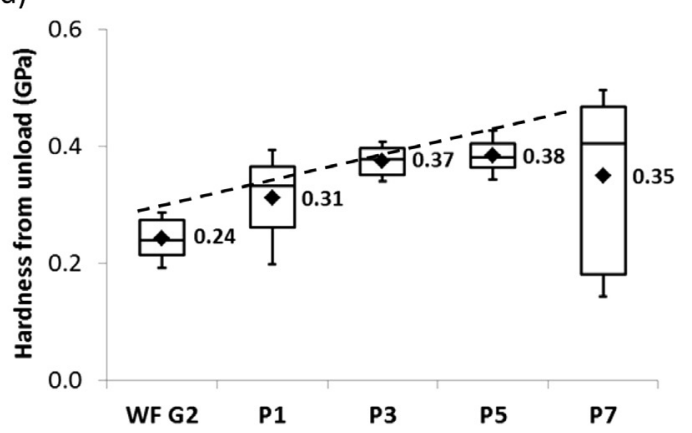

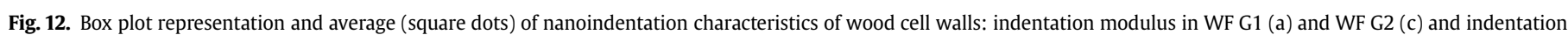
hardness in WF G1 (b) and WF G2 (d) through the processing cycles.

(around $0.1 \% \mathrm{w}$ ), these can be completely consumed by the successive process cycles [37]. During the rheological tests performed at $180{ }^{\circ} \mathrm{C}$, additional chain scissions can be involved.

Then SEC results indicate a progressive decrease of $\overline{\mathrm{Mn}}$ with the processing cycles for PP/WF G1 and PP/WF G2. This decrease seems to be more important from P1 to P7 for PP/WF G2 (-34\%) compared to PP/WF G1 (-16\%). This result could be related to the coarse particles observed for WF G2 which accentuate shear rates during processing. Moreover $\overline{\mathrm{Mw}}$ values remain independent of the processing cycles regarding the standard deviation. This led to conclude that an end-chain scission should occur rather than a random chain scission when PP/WF composites are submitted to successive processing cycles. Otherwise, a decrease of $\overline{\mathrm{Mn}}$ with a higher polydispersity index (Ip) can be observed at P3 for both materials. A similar tendency was obtained by Bahlouli et al. [36] while performing multiple extrusion runs on PP composites. Thus the Ip increase at the third cycle is attributed to the increase of the number of short to medium-sized chains induced by the chain scission described above. After 3 cycles, the number of long chains is reduced leading to a decrease of the polydispersity index (IP).
Newtonian viscosities indicated in Table 3 show for every material a progressive decrease with processing cycles. In the literature, numerous works deals with the processing of virgin or postconsumer neat PP. It was shown that the viscosity decreased after several processing cycles. This phenomenon was attributed to chain scission and thermal-oxidation of PP during the high-shear level processing [11-13]. As only $\overline{\mathrm{Mn}}$ values decrease with processing cycles, it can be proposed that an end-chain scission mechanism is the most relevant in our case. Otherwise, the addition of wood flour induces a higher viscosity because of the restriction of the chain mobility and possible bonds between wood particles and PP matrix as already supposed with SEC results. Moreover, the smaller particles (G1) cause a higher viscosity due to a greater specific surface which was also observed by Stark and Berger [2]. No difference between both composites can be observed from P5 as the particle sizes are quite the same.

As chain scissions and thermal treatments are occurring, one can expect for change in crystallinity with the processing cycles (Table 4). A slight increase of crystallinity can be noticed with the addition of wood flour. It may be due to a nucleating effect of wood. Otherwise, the neat PP crystallinity seems sparsely affected by the
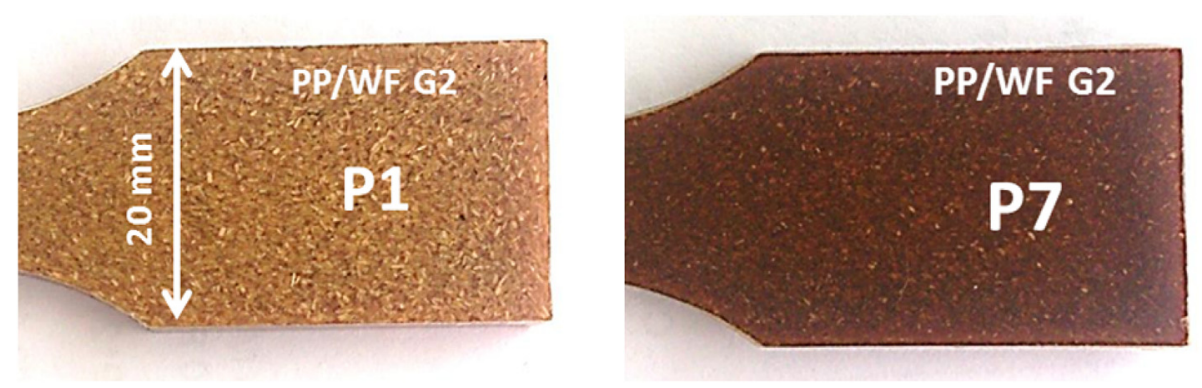

Fig. 13. Surface color change of PP/WF G2 from P1 to P7. 
Table 3

Average molecular weight in number $\overline{\mathrm{Mn}}$ and in weight $\overline{\mathrm{Mw}}$, polydispersity index and Newtonian viscosity as a function of the number of processing cycles.

\begin{tabular}{|c|c|c|c|c|c|}
\hline Materials & Cycles & $\overline{\mathrm{Mn}}(\mathrm{g} / \mathrm{mol})^{\mathrm{a}}$ & $\overline{\mathrm{Mw}}(\mathrm{g} / \mathrm{mol})^{\mathrm{b}}$ & $\mathrm{Ip}=\overline{\mathrm{Mw}} / \overline{\mathrm{Mn}}$ & $\eta_{0}(\text { Pa.s })^{c}$ \\
\hline \multirow[t]{5}{*}{ Neat PP } & after extrusion & 80,030 & 286,260 & 3.6 & - \\
\hline & $\mathrm{P} 1$ & 68,870 & 281,800 & 4.1 & $4698 \pm 100$ \\
\hline & P3 & 65,540 & 296,150 & 4.5 & $4210 \pm 369$ \\
\hline & P5 & 87,650 & 281,300 & 3.2 & $2830 \pm 240$ \\
\hline & P7 & 70,000 & 293,570 & 4.2 & $2410 \pm 46$ \\
\hline \multirow[t]{5}{*}{ PP/WF G1 } & after extrusion & 88,800 & 334,010 & 3.8 & - \\
\hline & P1 & 115,080 & 348,010 & 3 & $7787 \pm 285$ \\
\hline & P3 & 66,630 & 332,510 & 5.3 & $8024 \pm 69$ \\
\hline & P5 & 105,660 & 330,680 & 3.1 & $6602 \pm 438$ \\
\hline & P7 & 96,900 & 338,830 & 3.5 & $5671 \pm 220$ \\
\hline \multirow[t]{5}{*}{ PP/WF G2 } & after extrusion & 71,760 & 336,040 & 4.7 & - \\
\hline & P1 & 109,360 & 328,450 & 3 & $7055 \pm 421$ \\
\hline & P3 & 66,720 & 323,840 & 5.1 & $6289 \pm 268$ \\
\hline & P5 & 94,630 & 332,110 & 3.5 & $6464 \pm 174$ \\
\hline & P7 & 72,580 & 349,050 & 4.8 & $5416 \pm 266$ \\
\hline
\end{tabular}

a Average value with a $3 \%-5 \%$ standard deviation.

b Average value with a $5 \%-8 \%$ standard deviation.

c Newtonian viscosity measured at $180{ }^{\circ} \mathrm{C}$.

Table 4

Crystallinity percentages from 1 to 7 processing cycles by DSC.

\begin{tabular}{lllllll}
\hline \multirow{2}{*}{ Number of processing cycles } & \multicolumn{6}{l}{ Crystallinity percentages } \\
\cline { 2 - 7 } & \multicolumn{2}{l}{ Neat PP } & PP/WF G1 & \multicolumn{2}{l}{ PP/WF G2 } \\
\hline 1 & $46 \%$ & $\pm 0.8 \%$ & $47 \%$ & $\pm 1 \%$ & $50 \%$ & $\pm 1.5 \%$ \\
3 & $47 \%$ & $\pm 0.4 \%$ & $52 \%$ & $\pm 0.2 \%$ & $53 \%$ & $\pm 1.4 \%$ \\
5 & $47 \%$ & $\pm 0.2 \%$ & $51 \%$ & $\pm 0.6 \%$ & $54 \%$ & $\pm 1.1 \%$ \\
7 & $45 \%$ & $\pm 0.6 \%$ & $46 \%$ & $\pm 0.2 \%$ & $52 \%$ & $\pm 1.5 \%$ \\
\hline
\end{tabular}
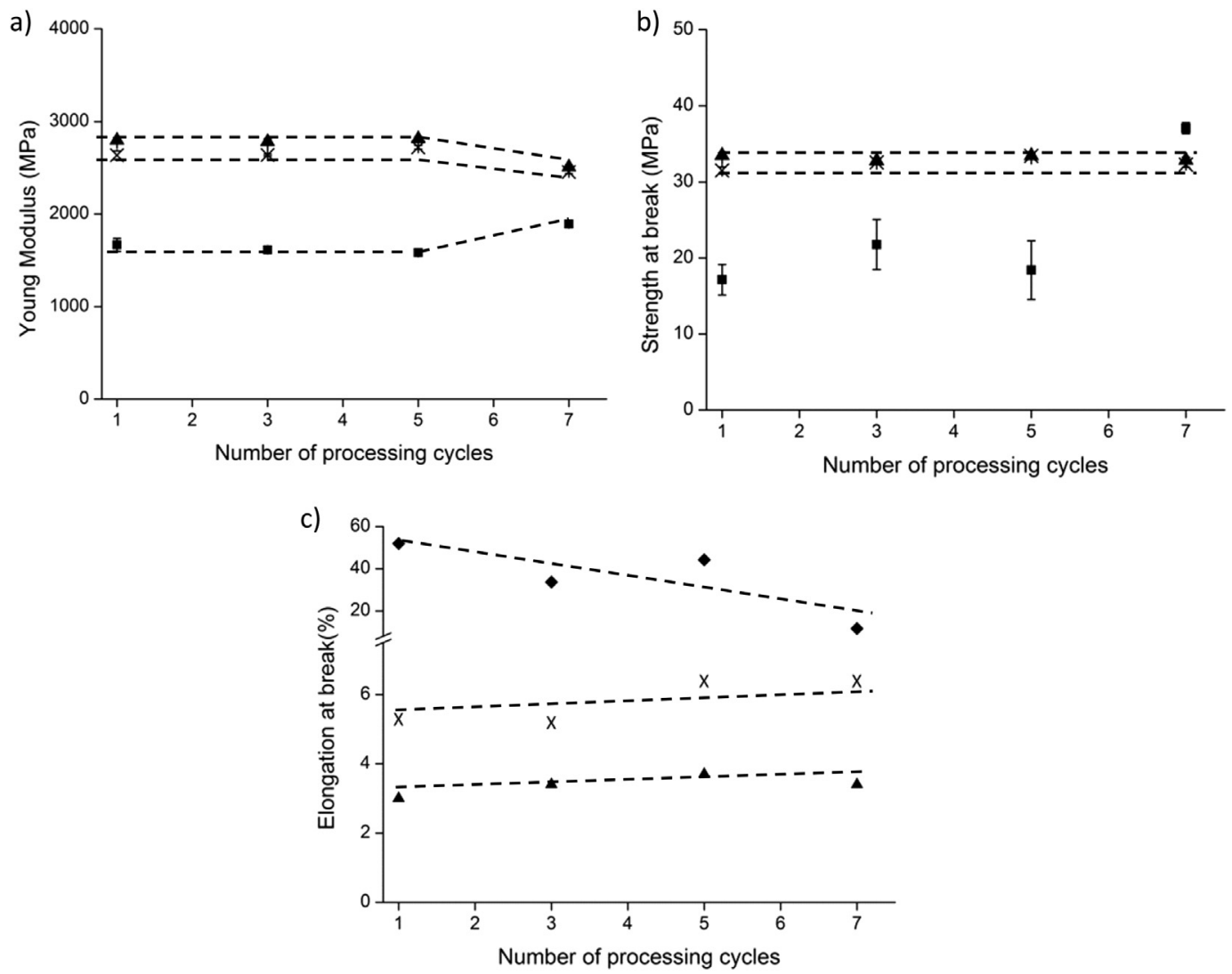

Fig. 14. Young modulus (a), strength at break (b) and elongation at break (c) measured by tensile test at 1, 3, 5 and 7 processing cycles of neat PP ( G2( $\mathbf{\Delta})$. processing cycles while $\mathrm{PP} / \mathrm{WF}$ the composites show an increase especially between P1 and P3. This corroborates the chain scission phenomenon previously discussed. No influence of the particle size can be underlined.

\subsubsection{Evolution of composite mechanical properties}

Fig. 14 presents the tensile properties obtained for the neat PP and for PP/WF G1 and G2 composites from 1 to 7 processing cycles. Concerning the behavior of neat PP up to 5 processing cycles, a slight increase in Young modulus and strength at break and a gradual decrease of elongation at break are observed. This suggests a prevalent chain scission phenomenon up to 5 cycles according to the decrease in the Newtonian viscosity (Table 3). At 7 cycles, an increase in modulus and strength at break occurs and suggests a possible simultaneous crosslinking mechanism.

For every composite, it can be noticed that the tensile stiffness is well preserved along 5 processing cycles and then decreases. The strength at break remains similar until the 7 processing cycles as a gradual increase of the elongation at break occurs. The good preservation of the tensile stiffness and strength along the processing cycles corroborate well the tendency found by Bourmaud and Baley [9] for a flax fiber composite which reveals that the natural fiber bundles split into finer fibers during the process and that it is not detrimental to the composite mechanical performances. Otherwise, it is well known that higher fiber size produces higher strength and elasticity but lower elongation $[2,38]$ due to a favored crack propagation. It can be slightly observed on the present tensile results. Both composites show a slight increasing elongation with the processing cycles because the particle size lessens as the crack propagation. 

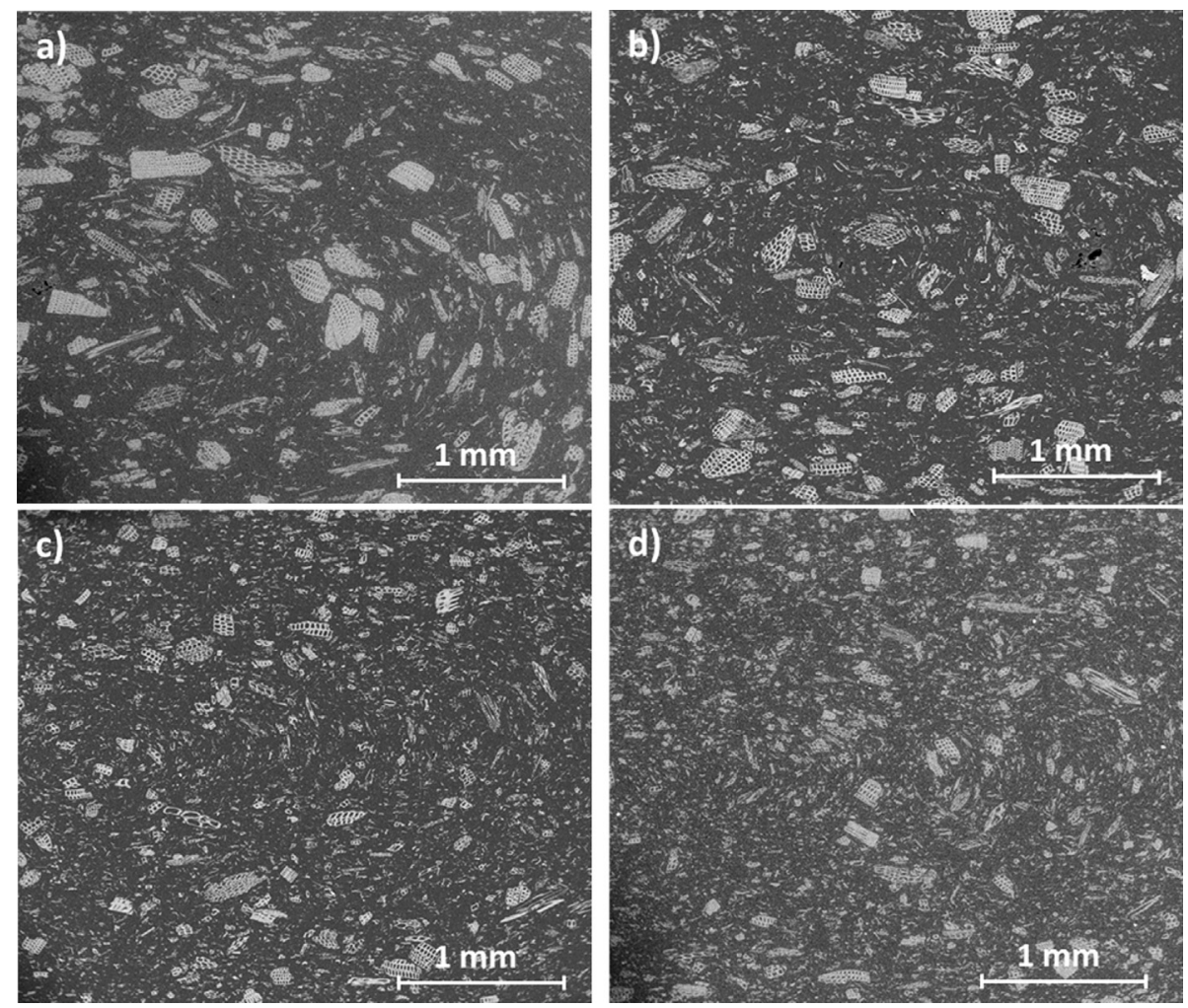

Fig. 15. SEM micrographs of transversal cross sections of PP/PPgma/WF G2 at P1 (a), P3 (b), P5 (c) and P7 (d) (magnification $\times 80$ ).

3.3. Effect of the addition of PPgma on the composites properties during the processing cycles

\subsubsection{Evolution of wood flour particles}

By comparing SEM pictures of PP/WF G2 and PP/PPgma/WF G2 at P1 (Figs. 9 and 15 respectively), the wood particles show a similar breakdown because of the processing cycles with a progressive improvement of particle dispersion.

Fig. 16 shows the equivalent diameter of WF G2 in the PP/ PPgma/WF composite and indicate the same evolution that PP/WF. Thus, the coupling agent does not impact the breakdown tendency of wood particles at these conditions and content. Moreover, the largest decrease is also observed after the first cycle because of the high sensitivity of coarse particles. The impact of the reprocessing

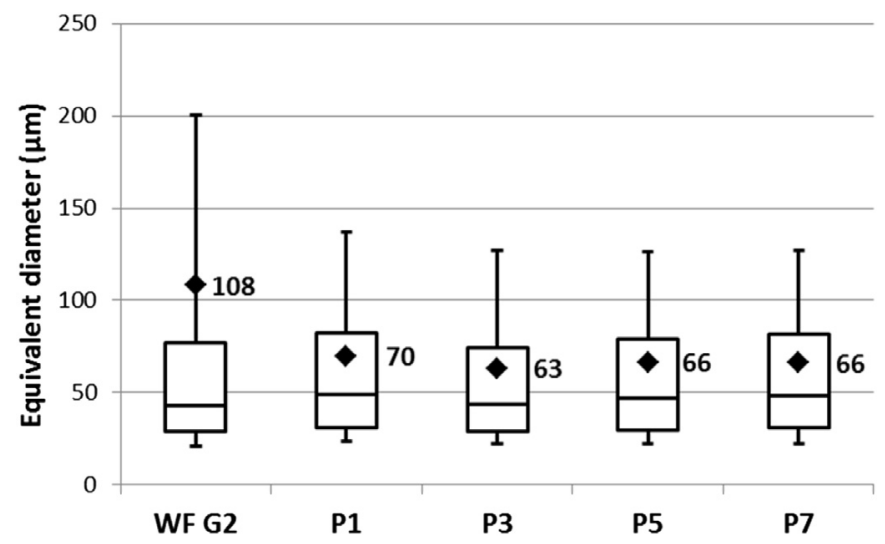

Fig. 16. Box-plot representation and average (square dots) of the equivalent diameter of WF G2 in the PP/PPgma/WF composite as a function of processing cycles. cycles shows the same tendency than PP/WF. So, the addition of PPgma does not influence the particle breakdown.

Fig. 17 indicates the equivalent diameter distribution for WF G2 in the presence of PPgma. The tendency is the same than PP/WF and also suggests that the wider particles at the initial state were nondetected because of their high lignin content. Indeed, the number of particles between $50 \mu \mathrm{m}$ and $220 \mu \mathrm{m}$ increases.

Fig. 18 indicates nanoindentation results of WF G2 while added to PP/PPgma/WF. Previous nanoindentation results in WF G2 into PP/WF (Fig. 12) have shown that no clear tendency concerning the modulus can be observed through the cycles despite maximum values at P3 and P5. Similarly to PP/WF G2, PP/PPgma/WF G2 composite shows that the wood particle hardness increases until

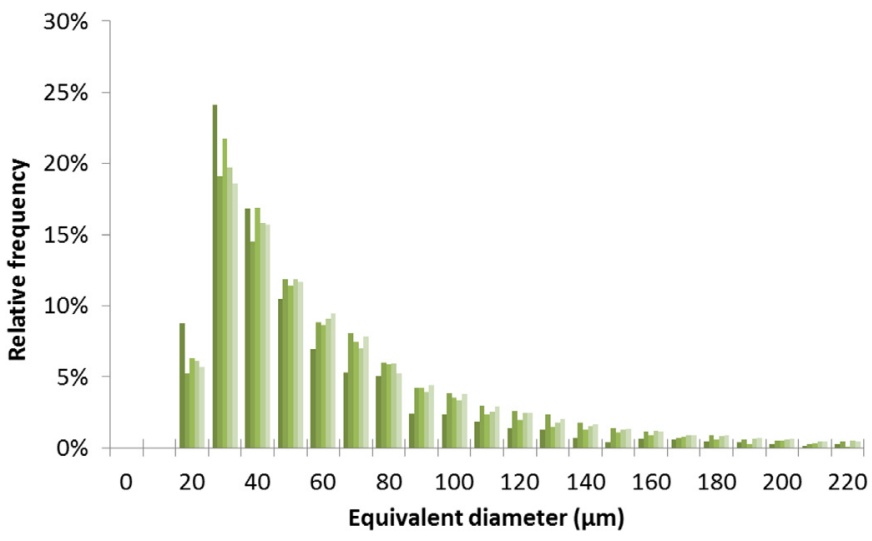

Fig. 17. Relative frequency by number of the particle equivalent diameter of WF G2 in the PP/PPgma/WF composite as a function of processing cycles from the initial state (darker color) to P7 (lighter color).(For interpretation of the references to colour in this figure legend, the reader is referred to the web version of this article.) 

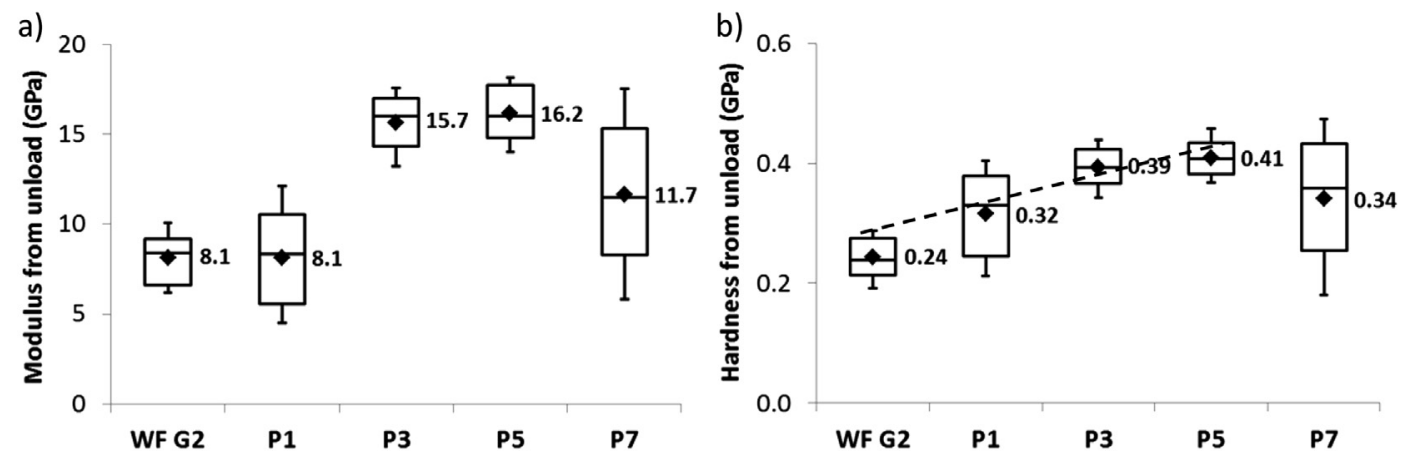

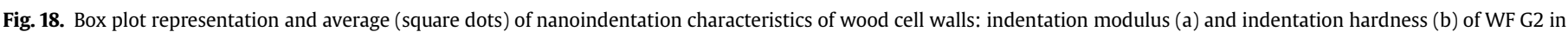
the PP/PPgma/WF composite through the processing cycles.

the 5th cycle (P5). In this present case, modulus and hardness show similar tendency with the addition of PPgma. A degradation and migration phenomenon of hemicellulose and lignin can explain these results. No influence from PPgma was detected on nanoindentation results.

\subsubsection{Evolution of PP matrix}

Average molecular weight results for PP/PPgma/WF G2 are presented in Table 5. A significant decrease of $\overline{\mathrm{Mn}}(-53 \%)$ and $\overline{\mathrm{Mw}}$ $(-10 \%)$ is observed at P1 in presence of PPgma due to the incorporation of low molecular weight chains. During processing, the presence of PPgma has a significant effect on the average chain length. Indeed a progressive increase of $\overline{\mathrm{Mn}}$ is observed for PP/ PPgma/WF G2 as a decrease was obtained without PPgma This phenomenon can be explained by a part of the PPgma which is not bound at the first cycle (P1) because the process parameters were not sufficient to initiate all the possible links between the coupling agent and the wood hydroxyl groups. The processing may induce a better reactivity by a repeated thermal and shear solicitation on the PPgma. Moreover, the increased polydispersity index after 7 cycles corroborate this hypothesis contrary to PP/WF where only chain scission was observed.

Concerning the Newtonian viscosity evolution, it was previously observed that $\mathrm{PP} / \mathrm{WF}$ G2 composite viscosity shows a gradual decrease as PP/PPgma/WF G2 shows a very low viscosity at P1 (due to the molecular weight of PPgma) and then, an increase close to the other composites. The viscosity results reveal to be well correlated to the SEC results concerning the chain scission tendency and the lack of reactivity of PPgma at the first cycle. Otherwise, the complex viscosity reaches a maximum value at the third cycle and a decrease afterward. It can be explained by a competition between chain branching and chain scission phenomena at this stage.

Crystallinity evolution is summarized in Table 6. Results show that the addition of PPgma does not induce a nucleating effect with wood flour as the crystallinity of PP/PPgma/WF is similar to neat PP. Otherwise, as already seen for PP/WF G1 and G2, PP/PPgma/WF shows an increase in crystallinity which also corroborates a slight chain phenomenon at the latest cycles.

Table 5

Average molecular weight in number $\overline{\mathrm{Mn}}$ and in weight $\overline{\mathrm{Mw}}$, polydispersity index and Newtonian viscosity as a function of the number of processing cycles of PP PPgma/WF G2 composite.

\begin{tabular}{llllll}
\hline Materials & Cycles & $\overline{\mathrm{Mn}}(\mathrm{g} / \mathrm{mol})$ & $\overline{\mathrm{Mw}}(\mathrm{g} / \mathrm{mol})$ & $\mathrm{Ip}=\overline{\mathrm{Mw}} / \overline{\mathrm{Mn}}$ & $\eta_{\mathrm{o}}$ (Pa.s) \\
\hline PP/PPgma/WF G2 & P1 & 51,440 & 299,110 & 5.8 & $4058 \pm 244$ \\
& P3 & 73,650 & 308,630 & 4.2 & $6424 \pm 173$ \\
& P5 & 80,120 & 308,510 & 3.9 & $5688 \pm 237$ \\
& P7 & 81,190 & 290,640 & 3.6 & $4194 \pm 411$ \\
\hline
\end{tabular}

\subsubsection{Evolution of composite mechanical properties}

Fig. 19 shows the tensile properties of the PP/PPgma/WF G2 composites. It can be observed that the addition of PPgma induces greater stiffness and strength thanks to a compatibilisation effect as already seen by Kord [4]. Concerning the reprocessing behavior, the tendency is the same with the free-PPgma composite: the modulus and strength remain quite stable while the elongation increases because of the particle size reduction.

\section{Conclusion}

This paper aimed to evaluate the influence of the wood particle size and of a PPgma coupling agent on the degradation of spruce wood flour reinforced PP composites after grinding-injection molding cycles (up to 7 cycles)

Concerning the comparison between WF G1 and WF G2, the numerous results have shown a similar tendency. Nanoindentation measurements have shown a hardening phenomenon of wood flour particles through the cycles which can be explained by a progressive degradation of extractives and hemicellulose and migration of lignin. Particle equivalent diameter measurements revealed that the coarser particles are more sensitive to breakdown during the processing cycles. Furthermore, wood particles size remains quite stable globally while the dispersion into PP is improved during the cycles. The microstructure assessment determined by SEC, rheometer and DSC tests have shown a chain scission phenomenon. The tensile tests indicate a very good stability of the studied composites until 5 cycles. As the results between both wood flour sizes were quite similar, further studies with greater size range can show more significant tendencies.

Although the addition of PPgma as a coupling agent has presented a high impact on tensile properties, no impact was observed on nanoindentation results. Wood cell wall hardness shows the same tendency than PP/WF G2 explained by a possible hemicellulose and lignin degradation. Particle size measurements revealed a similar trend during the cycles with PP/WF G2. SEC, rheometer and DSC results have shown a lack of reactivity of PPgma at the first cycles and a slight chain scission at the latest cycles.

Table 6

Crystallinity percentages from 1 to 7 processing cycles for PP/WF G2 and PP/PPgma/ WF G2 composites.

\begin{tabular}{lllll}
\hline \multirow{2}{*}{ Number of processing cycles } & \multicolumn{4}{l}{ Crystallinity percentages } \\
\cline { 2 - 5 } & PP/WF G2 & \multicolumn{2}{l}{ PP/PPgma/WF G2 } \\
\hline 1 & $50 \%$ & $\pm 1.5 \%$ & $45 \%$ & $\pm 3.3 \%$ \\
3 & $53 \%$ & $\pm 1.4 \%$ & $49 \%$ & $\pm 1.2 \%$ \\
5 & $54 \%$ & $\pm 1.1 \%$ & $47 \%$ & $\pm 0.8 \%$ \\
7 & $52 \%$ & $\pm 1.5 \%$ & $46 \%$ & $\pm 0.9 \%$ \\
\hline
\end{tabular}



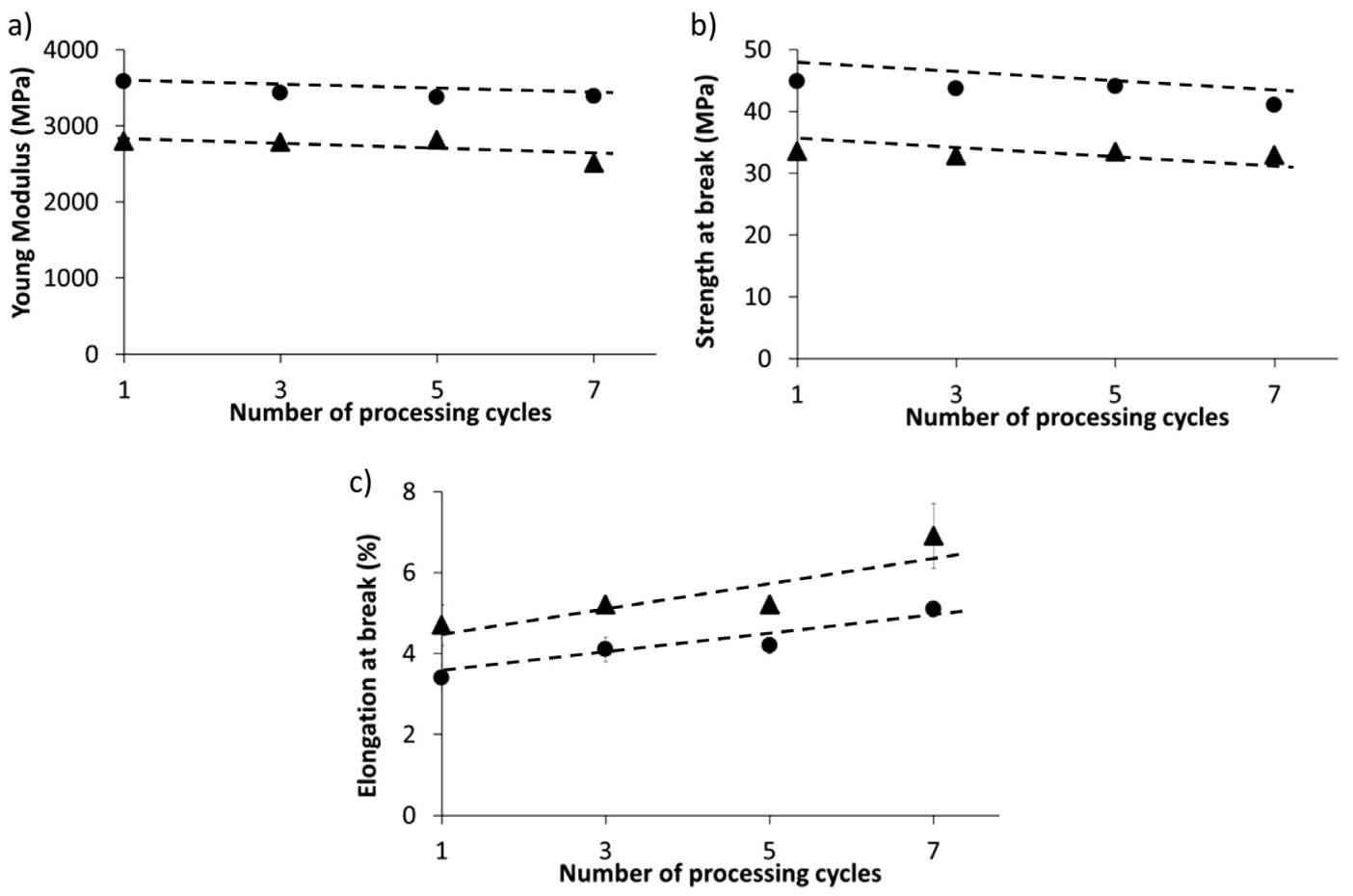

Fig. 19. Young modulus (a), strength at break (b) and elongation at break (c) measured by tensile test at 1, 3, 5 and 7 processing cycles of PP/WF G2 ( $\mathbf{\Delta}$ ) and PP/PPgma/WF G2 ( ).

Afterwards, despite a hardening of wood particles and a chain scission phenomenon, wood flour reinforced PP composites revealed to be very stable through the cycles. Although a degradation of both components, the reprocessing is not very detrimental to the mechanical properties after 5 cycles in these conditions. For a better understanding, process parameters and other wood and coupling agent contents should be considered to assess numerous degradation levels.

Furthermore, others protocols for wood particle size measurements should be developed to detect lignin-rich particles for microscopic image processing and a way to analyze wood particles hemicellulose and lignin content after PP dissolution must be found to assess the chemical evolution of wood during the cycles.

\section{Acknowledgments}

Authors thank the ADEME for financial support (convention $\mathrm{n}^{\circ}$ 1101C0066, acronym ENOLIBIO "ENd Of LIfe of BIOcomposites"), Mr. Jean-Marie Taulemesse for his assistance with scanning electron microscopy, Mr. Alain Diaz for his cross-section preparation and Dr. Anne-Sophie Caro-Bretelle for her help with Aphelion software.

\section{References}

[1] Winandy JE, Stark NM, Clemons CM. Considerations in recycling of woodplastic composites. In: 5th global wood and natural fiber composites symposium; April 27-28, 2004 [in Kassel, Germany].

[2] Stark N, Berger MJ. Effect of species and particle size on properties of woodflour-filled polypropylene composites. Functional Fillers for thermoplastics \& thermosets. December 8-10, 1997 [in San Diego, USA].

[3] Maiti SN, Singh K. Influence of wood flour on the mechanical properties of polyethylene. J Appl Polym Sci 1986;32:4285-9. http://dx.doi.org/10.1002/ app.1986.070320341.

[4] Kord B. Influence of maleic anhydride on the flexural, tensile and impact characteristics of sawdust flour reinforced polypropylene composite. World Appl Sci J 2011;12:1014-6.

[5] Sombatsompop N, Yotinwattanakumtorn C, Thongpin C. Influence of type and concentration of maleic anhydride grafted polypropylene and impact modifiers on mechanical properties of PP/wood sawdust composites. J Appl Polym Sci 2005;97:475-84. http://dx.doi.org/10.1002/app.21765.

[6] Kim Hee-Soo, Lee Byoung-Ho, Choi Seung-Woo, Kim Sumin, Kim Hyun-Joong. The effect of types of maleic anhydride-grafted polypropylene (MAPP) on the interfacial adhesion properties of bio-flour-filled polypropylene composites. Compos Part A Appl Sci Manuf 2007;38(Issue 6):1473-82. http://dx.doi.org/ 10.1016/j.compositesa.2007.01.004.

[7] Krzysik AM, Youngquist JA. Bonding of air-formed woodfiber/polypropylene fiber composites. Int J Adhesion Adhesives 1991;11:235-40.

[8] Beg MDH, Pickering KL. Reprocessing of wood fiber reinforced polypropylene composites. Part I, effect on physical and mechanical properties. Compos Part A 2008;39:1091-100. http://dx.doi.org/10.1016/j.compositesa.2008.04.013.

[9] Bourmaud A, Baley C. Investigations on the recycling of hemp and sisal fiber reinforced polypropylene composites. Polym Degrad Stab 2007;92:1034-45. http://dx.doi.org/10.1016/j.polymdegradstab.2007.02.018.

[10] Joseph PV, Joseph K, Thomas S. Effect of processing variables on the mechanical properties of sisal-fiber-reinforced polypropylene composites. Compos Sci Technol 1999;59:1625-40. http://dx.doi.org/10.1016/S0266-3538(99) 00024-X.

[11] Guerrica-Echevarria G, Eguiazabal JI, Nazabal J. Effects of processing conditions on the properties of unfilled and talc-filled polypropylene. Polym Degrad Stab 1996;53:1-8. http://dx.doi.org/10.1016/0141-3910(96)00018-3.

[12] Xiang Q, Xanthos M, Mitra S, Patel SH, Guo J. Effects of melt processing on volatile emissions and structural/rheological changes of unstabilized polypropylene. Polym Degrad Stab 2002;77:93-102. http://dx.doi.org/10.1016/ S0141-3910(02)00083-6.

[13] Martins MH, De Paoli MA. Polypropylene compounding with post-consumer material: II. Reprocessing. Polym Degrad Stab 2002;78:491-5. http:/ dx.doi.org/10.1016/S0141-3910(02)00195-7.

[14] Jäger $A$, Bader $T$, Hofstetter $K$, Eberhardsteiner J. The relation between indentation modulus, microfibril angle, and elastic properties of wood cell walls. Compos Part A Appl Sci Manuf 2011;42:677-85. http://dx.doi.org/ 10.1016/j.compositesa.2011.02.007.

[15] Bourmaud A, Baley C. Effects of thermo mechanical processing on the mechanical properties of biocomposite flax fibers evaluated by nanoindentation. Polym Degrad Stab 2010;95:1488-94. http://dx.doi.org/10.1016 j.polymdegradstab.2010.06.022.

[16] Gindl W, Reifferscheid M, Adusumalli R-B, Weber H, Röder T, Sixta H, et al. Anisotropy of the modulus of elasticity in regenerated cellulose fibres related to molecular orientation. Polymer 2008;49:792-9. http://dx.doi.org/10.1016/ j.polymer.2007.12.016.

[17] Wei G, Bhushan B, Torgerson PM. Nanomechanical characterization of human hair using nanoindentation and SEM. In: Ultramicroscopy proceedings of the sixth international conference on scanning probe microscopy, sensors and nanostructures, vol. 105; 2005. p. 248-66. http://dx.doi.org/10.1016/ j.ultramic.2005.06.033. 
[18] Wei G, Bhushan B. Nanotribological and nanomechanical characterization of human hair using a nanoscratch technique. In: Ultramicroscopy proceedings of the seventh international conference on scanning probe microscopy, sensors and nanostructures, vol. 106; 2006. p. 742-54. http://dx.doi.org/10.1016/ j.ultramic.2005.12.009.

[19] Gindl W, Schöberl T. The significance of the elastic modulus of wood cell walls obtained from nanoindentation measurements. Compos Part A Appl Sci Manuf 2004;35:1345-9. http://dx.doi.org/10.1016/j.compositesa.2004.04.002.

[20] Tze WTY, Wang S, Rials TG, Pharr GM, Kelley SS. Nanoindentation of wood cell walls: continuous stiffness and hardness measurements. Compos Part A Appl Sci Manuf 2007;38:945-53. http://dx.doi.org/10.1016/j.compositesa.2006.06.018.

[21] Yu Y, Fei B, Zhang B, Yu X. Cell-wall mechanical properties of bamboo investigated by in-situ imaging nanoindentation. Wood Fiber Sci 2007;39: 527-35.

[22] Bourmaud A, Baley C. Rigidity analysis of polypropylene/vegetal fibre composites after recycling. Polym Degrad Stab 2009;94:297-305. http:/ dx.doi.org/10.1016/j.polymdegradstab.2008.12.010.

[23] Le Moigne N, van den Oever M, Budtova T. A statistical analysis of fibre size and shape distribution after compounding in composites reinforced by natural fibres. Compos Part A Appl Sci Manuf 2011;42(Issue 10):1542-50. http:// dx.doi.org/10.1016/j.compositesa.2011.07.012.

[24] Sperling LH. Introduction to physical polymer Science. 4th ed. John Wiley \& Sons Inc; 2006, ISBN 9780471757115. p. 244.

[25] Jin W, Singh K, Zondlo J. Pyrolysis kinetics of physical components of wood and wood-polymers using isoconversion method. Agriculture 2013;3:12-32. http://dx.doi.org/10.3390/agriculture3010012.

[26] Gacitua W, Ballerini A, Lasserre JP, Bahr D. Nanoindentations and ultrastructure in eucalyptus nitens with micro and mesocracks. Maderas Cienc Tecnol 2007;9:259-70. http://dx.doi.org/10.4067/S0718-221X2007000300006.

[27] Bytebier K, Arnould O, Arinero P, Clair B, Alméras T. Towards nanomechanica characterization of developing wood cell walls at different maturation steps. In: 6th plant biomechanics conference; 2009 [in Cayenne].

[28] Wimmer R, Lucas BN. Comparing mechanical properties of secondary and cell corner middle lamella in spruce wood. IAWA J 1997;18:77-88.
[29] Wimmer R, Lucas BN, Tsui TY, Oliver WC. Longitudinal hardness and Young's modulus of spruce tracheid seondary walls using nanoindentation technique. Wood Sci Technol 1997;31:131-41. http://dx.doi.org/10.1007/BF00705928.

[30] Gindl W, Gupta HS, Grünwald C. Lignification of spruce tracheid secondary cell walls related to longitudinal hardness and modulus of elasticity using nano-indentation. Can J Bot 2002;80:1029-33. http://dx.doi.org/10.1139/ b02-091.

[31] Eder M, Arnould O, Dunlop JC, Hornatowska J, Salmén L. Experimental micromechanical characterisation of wood cell walls. Wood Sci Technol 2013;47:163-82. http://dx.doi.org/10.1007/s00226-012-0515-6.

[32] Ausias G, Bourmaud A, Coroller G, Baley C. Study of the fibre morphology stability in polypropylene-flax composites. Polym Degrad Stab June 2013;98(Issue 6):1216-24. http://dx.doi.org/10.1016/j.polymdegradstab.2013.03.006.

[33] Konnerth J, Gierlinger N, Keckes J, Gindl W. Actual versus apparent within cell wall variability of nanoindentation results from wood cell walls related to cellulose microfibril angle. J Mater Sci 2009:4399-406. http://dx.doi.org/ 10.1007/s10853-009-3665-7.

[34] Yildiz S, Gezer ED, Yildiz UC. Mechanical and chemical behavior of spruce wood modified by heat. Build Environ 2006;41(Issue 12):1762-6. http:/ dx.doi.org/10.1016/j.buildenv.2005.07.017.

[35] Hosseinaei O, Wang S, Rials TG, Xing C, Zhang Y. Effects of decreasing carbohydrate content on properties of wood strands. Cellulose 2011;18(Issue 3): 841-50. http://dx.doi.org/10.1007/s10570-011-9519-x.

[36] Bahlouli N, Pessey D, Raveyre C, Guillet J, Ahzi S, Dahoun A, et al. Recycling effects on the rheological and thermomechanical properties of polypropylenebased composites. Mater Des 2012;33:451-8. http://dx.doi.org/10.1016/ j.matdes.2011.04.049.

[37] Kazeem Najafi S. Use of recycled plastics in wood plastic composites - a review. Waste Manag 2013;33(Issue 9):1898-905. http://dx.doi.org/10.1016/ j.wasman.2013.05.017.

[38] Bouafif H, Koubaa A, Perré P, Cloutier A. Effects of fiber characteristics on the physical and mechanical properties of wood plastic composites. Compos Part A 2009;40:1975-81. http://dx.doi.org/10.1016/j.compositesa.2009.06.003. 